\title{
sciendo
}

CIVIL AND ENVIRONMENTAL ENGINEERING REPORTS

E-ISSN 2450-8594

CEER 2021; 31 (2): 0178-0217

DOI: $10.2478 /$ ceer-2021-0026

Original Research Article

\section{CALCULATING THE DYNAMIC IMPEDANCES OF FOUNDATIONS AND THEIR EFFECT ON THE SEISMIC RESPONSE OF STRUCTURES: ANALYTICAL AND NUMERICAL STUDY}

\author{
Radhwane BOULKHIOUT ${ }^{1}$, Salah MESSAST \\ LMGHU Laboratory, Department of Civil Engineering, University of 20 August 1955, \\ Skikda, 21000, Algeria
}

\begin{abstract}
This study evaluates the movement of a frame built on soft soil under seismic excitation taking into account soil-structure interaction. First, the study was evaluated using the finite element method, then, by using a substructure method which modelled the soil using springs and dampers in a linear and nonlinear study. Rheological models were determined using impedance functions, calculated using a numerical program CONAN. These dynamic impedances are shown in the displacement vector of a three-degrees-of-freedom frame, which was calculated on the basis of lateral forces distributed over the structure height using the equivalent static method. In this regard, two different calculation norms were chosen; RPA2003 and UBC97. Finally, a parametric study was carried out, based on the effects of soil densification and the foundation geometry on the response of the RC frame.
\end{abstract}

Keywords: soil-structure interaction, finite element method, substructure method, impedance functions, CONAN, equivalent static method, soil densification

\footnotetext{
${ }^{1}$ Corresponding author: LMGHU Laboratory, Department of Civil Engineering, University of 20 August 1955, Skikda, 21000, Algeria, e-mail: r.boulkhiout@univ-skikda.dz, tel. +213696267720
} 


\section{INTRODUCTION}

Dynamic soil-structure interaction is characterized by impedance functions that should be studied during the design of buildings and structures [1]. These dynamic impedances are considered as the main core in the dynamic calculation of structures. They denote the motion of a foundation subjected to a harmonic (seismic) load in the different translational and rotational degrees of freedom to ensure its proper functioning.

The importance of impedance functions in the dynamic calculation and their role in the rheological modelling of springs and dampers that drive motion in a particular direction, explains their use by several authors as being a necessary tool in the dynamic calculation. For instance, Lamb (1904) [2] studied the vibrations of a semi-finite linearly elastic medium under concentrated harmonic load. Reissner (1936) [3] analyzed the response of a disk placed on the surface of an isotropic and semi-finite elastic medium. This analysis revealed an energy dissipation by radiation as if the propagation medium has some damping characteristics. Based on these results, Sung (1953) [4] extended the works of Reissner to six degrees of freedom of foundation motion. The idea of comparing soil-foundation systems in vertical translation to a simple oscillator of constant stiffness and damping was first introduced by Lysmer (1965) [5]. This approach is commonly designated as a "Lysmer analogy" (see Figure 1). Early 1970 witnessed a further development in impedance calculation methods by presenting the results in the form of two parts, one real and the other imaginary, depending on the frequency. This includes impedance and displacement functions.

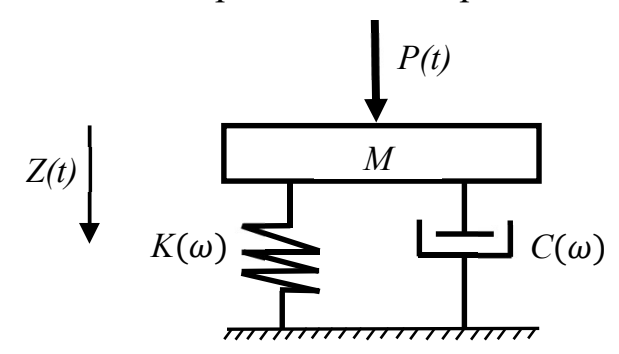

Fig. 1. Vertical impedance of a foundation 
Impedance functions are primarily linked to the foundation geometry, soil type, vibration mode as well as to the harmonic excitation [6]. They denote the response of a foundation under a harmonic load in a particular direction. Impedance functions represent a complex formula, which associates the independent static stiffnesses to the dimensionless frequency with a complex frequency number, helping to determine the exact magnitudes of the rheological models perfectly embedded [7].

One aspect of soil-structure interaction is damping which may occur due to the dynamic interaction at the soil-foundation interface. This damping may occur in different ways: soil-foundation contact, hysteretic behavior of the soil, or seismic waves radiation. In the literature, two types of damping can be observed, one is material corresponding to dissipation in the form of heat in the vicious materials determined using the nonlinear Kelvin-Voigt model [8], the other is geometric, and may be interpreted as the result of a transmission to the infinity of a part of the strain energy by radiation of seismic waves. It is defined using the imaginary part of dynamic impedances [9].

The behavior of the structures under seismic effect is mainly linked to the type of seating soil, in which the response of the structure change if the stiffness of the soil decreases [10]. Soil densification technique by compaction consists of improving soil mechanical properties by transmitting high-energy impacts into soft soils with low bearing capacity and high compressibility potentials. The impact creates body and surface waves which propagate through the soil. In the unsaturated soils, the waves move the grains and rearrange them in a denser way. In the saturated soils, the soil is liquefied and rearranged in a more compact state. In both cases, the reduction in voids and the increase of internal granular contact improved soil properties [11].

In the literature, several authors were interested in the dynamic calculation of structures under different soil conditions. For example, Edip et al. [12] analyzed the effects of soil on the frame responses using the finite element method under the impact of boundary type. Jaber et al. [13] applied the mohr-coulomb model to study the plastic effects of the soil on the behavior of multi-story buildings. Ada and Ayvaz [14] analyzed the effect of soil-structure interaction on two adjacent frames using the finite element method, taking into account the non-linearity of the soil. Edip et al. [15] applied a numerical simulation of soil-structure interaction problems including damper effects. This new approach coupled finite and infinite computational methods. Our contribution in this area is to illustrate the effect of the soil on the frame responses, using dynamic impedances in both linear and nonlinear cases, in which a mathematical equation allowing the calculation of the motion vector of a three-degrees-of-freedom frame, considered free-field at the base, was developed. Dynamic impedances were calculated using the cone 
method and CONAN software. On the other hand, the motion vector was dynamically calculated based on time and statically calculated by applying the equivalent static method. Then, we confirmed the presented method by applying the finite element method with absorbing boundaries. Finally, a parametric study was conducted to determine the effect of soil parameters and foundation geometry on the response of the structure.

\section{DYNAMIC IMPEDANCE CALCULATION METHODS}

Dynamic impedances are considered a primary tool in calculating the response of foundations under harmonic excitations in their different directions. Many researchers are interested in calculating these dynamic impedances using different methods; numerical, analytical, and experimental [16-20].

\subsection{Analytical method "cone model"}

Mathematical calculation of impedance functions based on the application of the cone method on a foundation at a particular depth from the surface of the soil and subjected to harmonic loads for the six degrees of freedom. The Cone model substitutes the elastic half-space with a truncated cone that may be considered as an elastic beam with a variable section [21-24], as shown in Figure 2.

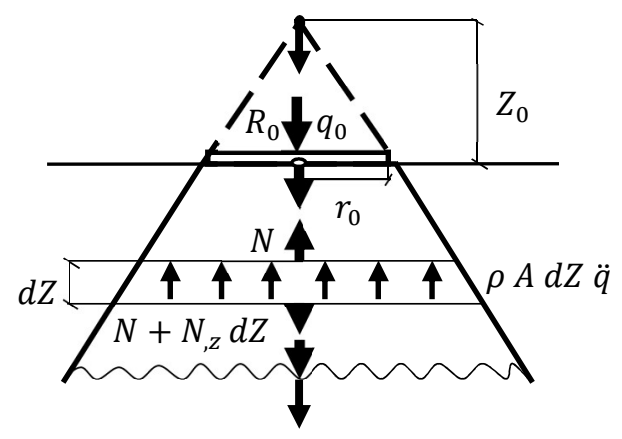

Fig. 2. Model of cone 


\subsubsection{Horizontal impedance}

Figure 3 presents a disk resting on a lower bar. This disk (foundation) has a radius $r_{0}$ and is subjected to a harmonic horizontal force $P_{0}$; the resulting displacement is $U_{0}$ at the soil-disk interface.

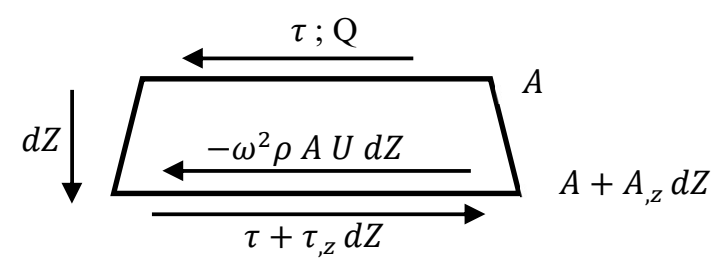

Fig. 3. A foundation subject to a horizontal force

Shear stress $\tau$ is given by the following formula:

$$
\begin{gathered}
\tau=\frac{Q}{A} \\
Q=G \cdot A \cdot U_{, z}
\end{gathered}
$$

Where, $A$ : Surface of foundation, $G$ : Shear modulus of soil, $Q$ : Horizontal force, $U$ : Horizontal displacement.

The equilibrium of horizontal forces gives:

$$
\begin{gathered}
\left(\tau+\tau_{, z} d Z\right)\left(A+A_{, z} d Z\right)-\tau \cdot A+\omega^{2} \cdot \rho \cdot U \cdot d Z\left(A+A_{, z} d Z\right)=0 \\
A \cdot \tau_{, z}+A_{, z} \cdot \tau+\omega^{2} \cdot \rho \cdot A \cdot U=0 \\
A \cdot\left(\frac{Q}{A}\right)_{, z}+A_{, z}\left(\frac{Q}{A}\right)+\omega^{2} \cdot \rho \cdot A \cdot U=0 \\
Q_{, z}+\left(\frac{A_{, z}}{A}\right) Q+\omega^{2} \cdot \rho \cdot A \cdot U=0
\end{gathered}
$$

Substituting equation (2.2) into equation (2.3) gives:

$$
\begin{gathered}
\left(G \cdot A \cdot U_{, z}\right)_{, z}+G \cdot A \cdot U_{, z}\left(\frac{A_{, z}}{A}\right)+\omega^{2} \cdot \rho \cdot A \cdot U=0 \\
G \cdot A \cdot U_{, z z}+G \cdot A_{, z} U_{, z}+\omega^{2} \cdot \rho \cdot A \cdot U=0 \\
U_{, z z}+\left(\frac{A_{, z}}{A}\right) U_{, z}+\left(\frac{\omega^{2} \rho}{G}\right) U=0
\end{gathered}
$$


Where, $\rho$ : Density of soil; $\omega:$ Frequency of excitation.

Shear wave velocity $V_{s}$ gives:

$$
V_{s}=\sqrt{\frac{G}{\rho}}
$$

Then, the equation (2.4) becomes:

$$
U_{, z z}+\left(\frac{A_{, z}}{A}\right) U_{, z}+\left(\frac{\omega^{2}}{V_{s}^{2}}\right) U=0
$$

From Figure 4, we have:

$$
\begin{aligned}
& A=\pi \cdot r_{0}^{2} \\
& \tan (\alpha)=\frac{r_{0}}{Z} \\
& r_{0}=Z \cdot \tan (\alpha) \\
& A=\pi \cdot Z^{2} \cdot \tan ^{2}(\alpha) \\
& A_{, z}=2 \cdot \pi \cdot Z \cdot \tan ^{2}(\alpha) \\
& \left(\frac{A_{, z}}{A}\right)=\frac{2}{Z}
\end{aligned}
$$

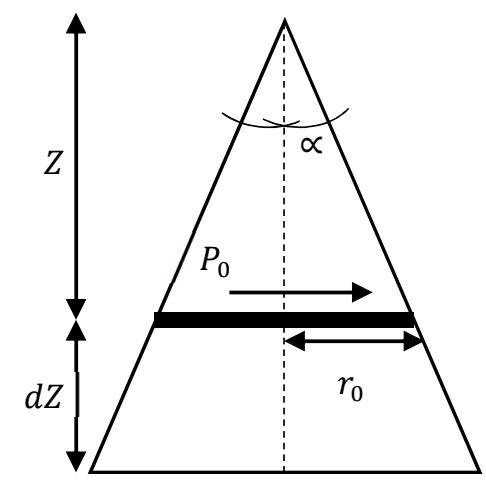

Fig. 4. Explanatory schema of the cone model

Where, $Z$ : Depth of foundation; $\alpha$ : Angle.

The equilibrium dynamic equation becomes:

$$
U_{, z z}+\left(\frac{2}{z}\right) U_{, z}+\left(\frac{\omega^{2}}{V_{s}^{2}}\right) U=0
$$




$$
\begin{aligned}
& \frac{1}{Z}\left[Z \cdot U_{, z z}+2 . U_{, z}+\left(\frac{\omega^{2}}{V_{S}^{2}}\right)(U Z)\right]=0 \\
& Z \cdot U_{, z z}+2 \cdot U_{, z}+\left(\frac{\omega^{2}}{V_{s}^{2}}\right)(U Z)=0
\end{aligned}
$$

We have:

$$
(U Z)_{, z z}=Z \cdot U_{, z z}+2 \cdot U_{, z}
$$

Hence, equation (2.8) becomes:

$$
(U Z)_{, z z}+\frac{\omega^{2}}{V_{s}^{2}}(U Z)=0
$$

Equation (2.9) is a second order equation of dynamic motion, which is solved as follows:

$$
\begin{gathered}
(U Z)=e^{i \cdot \gamma \cdot Z} \\
(U Z)_{, z z}=-\gamma^{2}(U Z)
\end{gathered}
$$

Equation (2.9) becomes:

$$
-\gamma^{2}(U Z)+\frac{\omega^{2}}{V_{s}^{2}}(U Z)=0
$$

The solution to equation (2.11) gives:

$$
\left.\begin{array}{l}
\gamma_{1}=+\frac{\omega}{V_{s}} \\
\gamma_{2}=-\frac{\omega}{V_{s}}
\end{array}\right\}
$$

Then $U Z$ is expressed as:

$$
(U Z)=A_{1} e^{-i\left(\frac{\omega}{V_{s}}\right) Z}+B_{1} e^{+i\left(\frac{\omega}{V_{s}}\right) Z}
$$

$A_{1}$ and $B_{1}$ are constants defined by the boundary conditions, the solution to the dynamic motion equation $U$, is as follows: 


$$
U=\frac{A_{1}}{Z} e^{-i\left(\frac{\omega}{V_{s}}\right) Z}+\frac{B_{1}}{Z} e^{+i\left(\frac{\omega}{V_{s}}\right) Z}
$$

The shear wave propagates in the direction $z \succ 0$. Therefore, the second term will be neglected.

Based on the cone model, we have:

$$
Z=r_{0} \cdot \cot (\alpha)
$$

If $Z=r_{0} \cdot \cot (\alpha)$ we have, $U(0)=U_{0}$ (Boundary condition):

$$
U\left[r_{0} \cdot \cot (\alpha)\right]=U_{0}
$$

Using equation (2.13):

$$
U\left[\left(r_{0} \cdot \cot (\alpha)\right]=\frac{A_{1}}{r_{0} \cot g(\alpha)} e^{-i\left(\frac{\omega}{V_{s}}\right) r_{0} \cot (\alpha)}\right.
$$

Using equations (2.14) and (2.15):

$$
A_{1}=r_{0} \cdot \cot (\alpha) e^{+i\left(\frac{\omega}{V_{s}}\right) r_{0} \cot (\alpha)} U_{0}
$$

Substituting the formula of $A_{1}$ into equation (2.13) gives:

$$
U=\frac{r_{0} \cot (\alpha)}{Z} e^{i \frac{\omega}{V_{s}}\left(r_{0} \cot (\alpha)-Z\right)} U_{0}
$$

Otherwise, based on horizontal forces equilibrium:

$$
P_{0}=-Q=-G \cdot A \cdot U_{, z}
$$




$$
U_{, z}=\frac{r_{0} \cot (\alpha)}{Z} e^{i \frac{\omega}{V_{s}}\left(r_{0} \cot (\alpha)-Z\right)}\left(\frac{1}{Z}+\frac{i \omega}{V_{s}}\right) U_{0}
$$

Hence, the applied force formula becomes:

$$
P_{0}=\frac{G \cdot \pi \cdot r_{0}}{\cot (\alpha)}\left(1+i \frac{\omega}{V_{s}} r_{0} \cot (\alpha)\right) U_{0}
$$

The formula of a dimensionless frequency is: $a_{0}=\frac{\omega \cdot r_{0}}{V_{s}}$ Then, equation (2.17) becomes:

$$
P_{0}=\frac{G \cdot \pi \cdot r_{0}}{\cot (\alpha)}\left(1+i a_{0} \cot (\alpha)\right) U_{0}
$$

The formula of $P_{0}$ can also be expressed as:

$$
P_{0}=k_{s}\left(k_{1}+i a_{0} c_{1}\right) U_{0}
$$

The comparison of equations (2.18) and (2.19) gives:

$$
\frac{G \cdot \pi \cdot r_{0}}{\cot (\alpha)}\left(1+i a_{0} \cot (\alpha)\right) U_{0}=k_{s}\left(k_{1}+i a_{0} c_{1}\right) U_{0}
$$

The formula of static impedance $k_{s}$, relative stiffness $k_{1}$, and relative damping $c_{1}$ is expressed as follows:

$$
\begin{gathered}
k_{s}=\frac{G \cdot \pi \cdot r_{0}}{\cot (\alpha)} \\
k_{1}=1 ; \forall a_{0} \\
c_{1}=\cot (\alpha) ; \forall a_{0}
\end{gathered}
$$

\subsubsection{Vertical impedance}

Figure 5 presents a foundation with a radius $r_{0}$, subjected to a harmonic vertical force $R_{0}$, and the resulting displacement is $q_{0}$ at the soil-disk interface. 


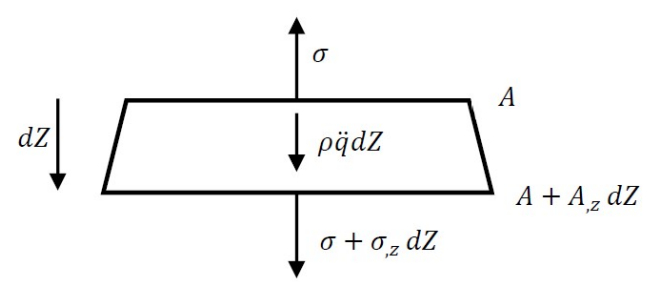

Fig. 5. A foundation subject to a vertical force

The vertical equilibrium equation gives:

$$
\begin{gathered}
\left(\sigma+\sigma_{, z} d Z\right)\left(A+A_{, z} d Z\right)-\sigma \cdot A+\omega^{2} \cdot \rho \cdot q\left(A+\frac{1}{2} A_{, z} d Z\right) d Z=0 \\
A \cdot \sigma_{, z}+A_{, z} \cdot \sigma+\omega^{2} \cdot \rho \cdot q=0 \\
\sigma_{, z}+\left(\frac{A_{, z}}{A}\right) \sigma+\omega^{2} \cdot \rho \cdot q=0
\end{gathered}
$$

Where, $q$ : Vertical displacement, $\sigma:$ Vertical stress.

Based on Hooke's law:

$$
\begin{aligned}
\sigma & =E \cdot q_{, z} \\
\sigma_{, z} & =E \cdot q_{, z z}
\end{aligned}
$$

Where, E: Young's modulus of soil.

Substituting equations (2.24) and (2.25) into equation (2.23), gives:

$$
q_{, z z}+\left(\frac{A_{, z}}{A}\right) q_{, z}+\frac{\rho}{E} \cdot \omega^{2} \cdot q=0
$$

The velocity of longitudinal wave $V_{l}$ gives: 


$$
V_{l}=\sqrt{\frac{E}{\rho}}
$$

The equilibrium equation becomes:

$$
\begin{aligned}
& q_{, z z}+\left(\frac{2}{Z}\right) q_{, z}+\left(\frac{\omega^{2}}{V_{l}^{2}}\right) \cdot q=0 \\
& \frac{1}{Z}\left(Z q_{, z z}+2 q_{, z}+\left(\frac{\omega^{2}}{V_{l}^{2}}\right) \cdot q Z\right)=0 \\
& Z q_{, z z}+2 q_{, z}+\left(\frac{\omega^{2}}{V_{l}^{2}}\right) \cdot q Z=0
\end{aligned}
$$

We have:

$$
(q Z)_{, z z}=Z q_{, z z}+2 q_{, z}
$$

Then, equation (2.28) becomes:

$$
(q Z)_{, z z}+\left(\frac{\omega^{2}}{V_{l}^{2}}\right) \cdot(q Z)=0
$$

The solution of equation (2.29) gives:

$$
\left.\begin{array}{l}
\gamma_{1}=+\frac{\omega}{V_{l}} \\
\gamma_{2}=-\frac{\omega}{V_{l}}
\end{array}\right\}
$$

The solution to the dynamic motion equation $q$ is given as follows:

$$
q=\frac{A_{1}}{Z} e^{-i\left(\frac{\omega}{V_{l}}\right) Z}+\frac{B_{1}}{Z} e^{+i\left(\frac{\omega}{V_{l}}\right) Z}
$$

$A_{1}$ and $B_{1}$ are constants defined by the boundary conditions $q(0)=q_{0}$, after applying the latter, the motion equation is expressed as follows:

$$
q=\frac{r_{0} \cot (\alpha)}{Z} e^{i \frac{\omega}{V_{l}\left(r_{0} \cot (\alpha)-Z\right)}} q_{0}
$$

We have:

$$
\begin{gathered}
R_{0}=\sigma_{0} \cdot A_{0} \\
R_{0}=E \cdot q_{, z}(0) \cdot A_{0}
\end{gathered}
$$




$$
R_{0}=\frac{E \cdot \pi \cdot r_{0}}{\cot (\alpha)}\left(1+i a_{0} \cot (\alpha)\right) q_{0}
$$

From equation (2.33), the static stiffness $k_{s}$, relative stiffness $k_{1}$, and relative damping $c_{1}$ formulae can be expressed as follows:

$$
\begin{gathered}
k_{s}=\frac{E \cdot \pi \cdot r_{0}}{\cot (\alpha)} \\
k_{1}=1 ; \forall a_{0} \\
c_{1}=\cot (\alpha) ; \forall a_{0}
\end{gathered}
$$

\subsection{Numerical method "CONAN program"}

In this study, the calculation of horizontal, vertical, rocking, and torsional impedance functions was achieved using the cone method by means of CONAN software. This allows the calculation of stiffness and damping dynamic coefficients at one or multiple excitation frequencies for a selected degree of freedom. Where: ' $H$ ' is the horizontal degree of freedom, ' $V$ ' is the vertical degree of freedom, ' $T$ ' is the torsional degree of freedom, and ' $R$ ' is the rocking degree of freedom.

\section{DESCRIPTION OF REFERENCE MODEL}

\subsection{Model of structure}

The structure is a three-floor reinforced concrete frame; each floor has a $5 \mathrm{~m}$ long span with a section of $40 \times 70 \mathrm{~cm}^{2}$. Column height is equal to $4 \mathrm{~m}(l=4 \mathrm{~m})$ with a section size of $40 \times 40 \mathrm{~cm}^{2}$. The structure rests on footings with square sections $2 \times 2 \mathrm{~m}^{2}$ (Figure 6). The

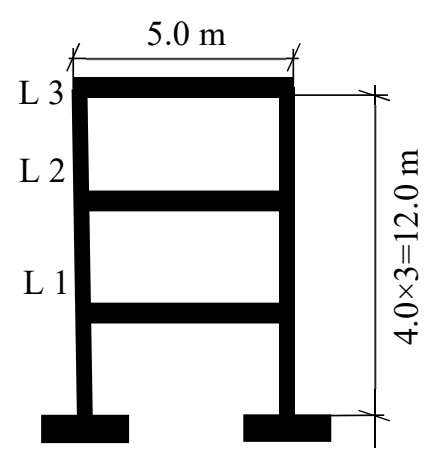

Fig. 6. Dimensions of the structure 
characteristics of the concrete material in the structure are given in Table 1.

Table 1. Parameters of structure

\begin{tabular}{|c|c|c|c|c|}
\hline$\rho_{c}\left(\mathbf{k N} / \mathbf{m}^{3}\right)$ & $f_{c k}$ (MPA) & $E_{c}$ (MPA) & $\mathbf{v}$ & $\xi$ \\
\hline 25 & 35 & 25000 & 0.2 & 0.05 \\
\hline
\end{tabular}

\subsection{Model of soil}

The soil under the structure has a dimension in 2-D of $70 \times 10 \mathrm{~m}^{2}$ (see Figure 7). It is intended to be homogeneous with a linear elastic behavior and a damping coefficient $\xi$. It is characterized by its density $\rho$ and behavior parameters as follows: shear modulus $G$, Poisson ratio $v$, and shear wave velocity $V_{s}$. The values of these parameters are provided in Table 2 .

Table 2. Parameters of soil

\begin{tabular}{|c|c|c|c|}
\hline$V_{s} \mathbf{( m / \mathbf { s } )}$ & $\rho\left(\mathbf{k N} / \mathbf{m}^{\mathbf{3}}\right)$ & $\mathbf{v}$ & $\boldsymbol{\xi}$ \\
\hline 300 & 20 & 0.3 & 0.05 \\
\hline
\end{tabular}

The shear modulus $G$ and elasticity modulus $E$ of the soil are calculated as follows:

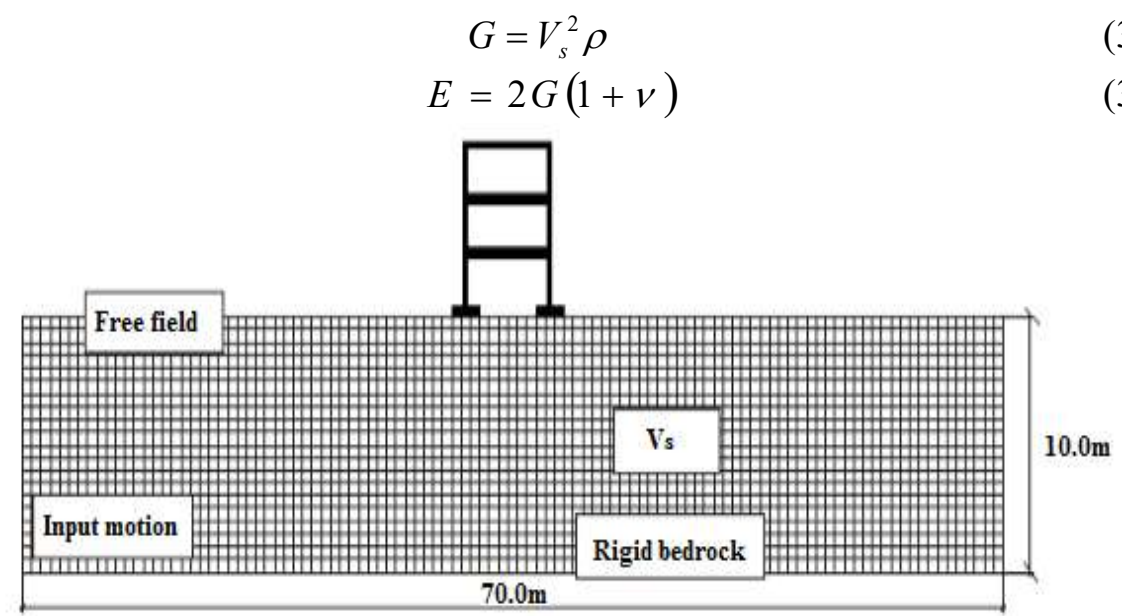

Fig. 7. Dimensions of soil under structure in 2-D 


\subsection{Seismic excitation}

The seismic load given for time analysis consists of several components of ElCentro earthquake acceleration. Figure 8 shows acceleration change in accordance with the different periods of the earthquake that had hit California on May 18, 1940.

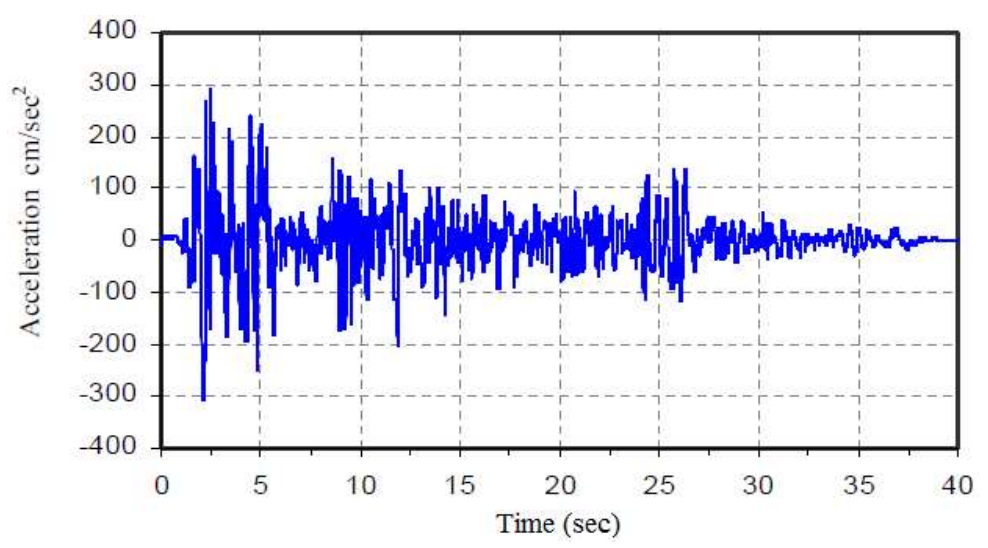

Fig 8. El-Centro accelerogram [25]

\section{RESULTS AND ANALYSIS}

\subsection{Dynamic impedance calculation}

The impedance functions of a foundation resting on a semi-finite, viscoelastic, homogeneous, and isotropic medium were calculated. Figures 9 to 12 show the variation of real and imaginary elements depending on the dimensionless frequency $a_{0}$ for the four degrees of freedom $<H ; V ; T ; R>$.

The stiffness coefficient remains at a constant value for the translational degrees of freedom versus an increase in the dimensionless frequency a0; however, in terms of torsional and rocking degrees of freedom, a relatively small decrease in this value was observed. 
The value of the damping coefficient is nil when the dimensionless frequency is equal to zero for the four degrees of freedom. In this case, there is no energy dissipation in the system. Afterwards, its value increased in the range from 0 to 0.5 for degrees of translation, then remained constant in the range from 0.5 to 4 . However, a proportionality between the damping coefficient and dimensionless frequency values was observed due to torsional and rocking motions.
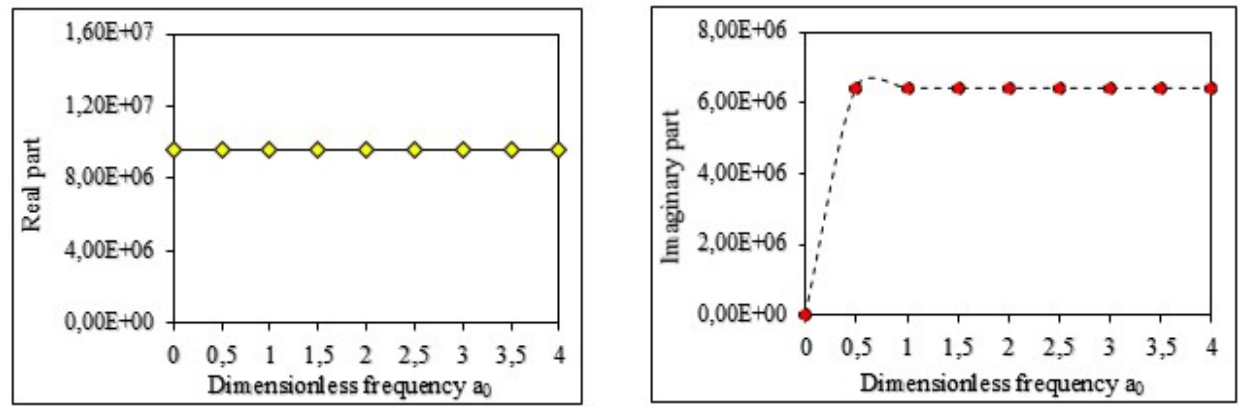

Fig. 9. Horizontal impedance versus the dimensionless frequency
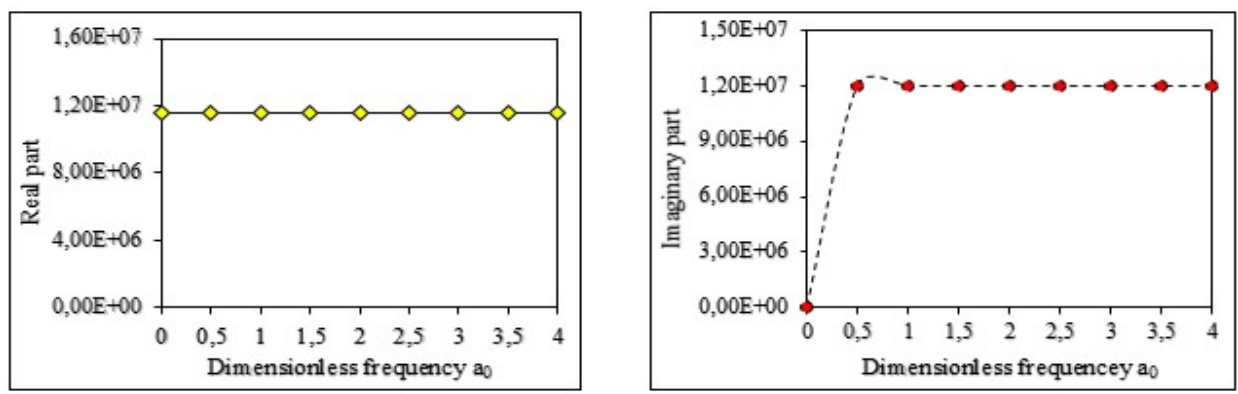

Fig. 10. Vertical impedance versus the dimensionless frequency
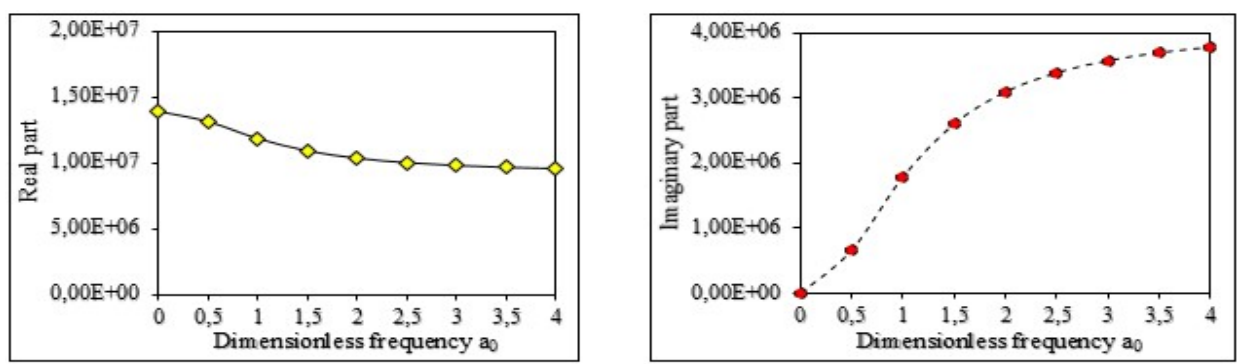

Fig. 11. Torsional impedance versus the dimensionless frequency 

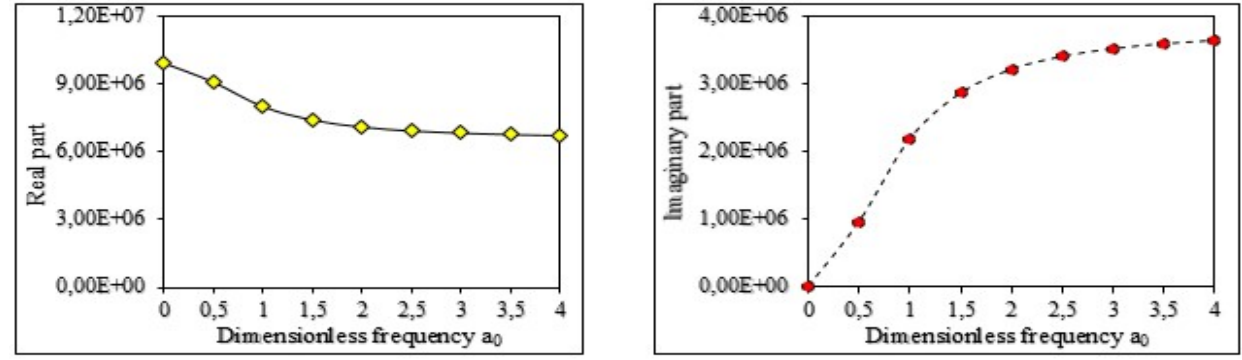

Fig. 12. Rocking impedance versus the dimensionless frequency

\subsection{Calculation of the frame displacement taking into consideration soil- structure interaction}

In the present study, the seismic response of a three-floor frame was evaluated based on its displacement, using two different methods. Firstly, the response was calculated by SAP2000 software using the finite element method (FEM), and secondly, by a mathematical method which uses the previously calculated dynamic impedances of the foundation. This method uses another method called "the equivalent static method" in order to determine the value of seismic force at the base and to allow its distribution over the frame height, in the form of concentrated lateral forces.

\subsubsection{Finite Element Method (FEM)}

The finite element method is considered as a method of solving the problem of the soil-structure interaction [26-28]. It involves breaking the domain down into finite elements limited by absorbent boundaries (see Figure 13). It is a method of discretization of the global functional into several functions related to each element. In each element, the unknown fields of displacement are represented by the Ritz method using a functional basis specific to each element, of which basis functions are referred to as interpolation functions. They were chosen in order to achieve continuity of the unknown fields while crossing the known boundaries of the elements. 


\subsubsection{Structure modelling}

The reinforced concrete superstructure was modelled as a monolithic structure with linear, elastic, and isotropic properties; it was discretized into several elements with a size of $50 \mathrm{~cm}$. For the material, we used Rayleigh damping (5\%) [29].

Rayleigh damping $[C]$ allows linear combining of mass matrix $[M]$ and structure stiffness $[K]$ as follows:

$$
[C]=\alpha[M]+\beta[K]
$$

Where, $\alpha$ and $\beta$ are two damping coefficients that can be calculated based on the coefficient, the first mode fundamental frequency $\omega_{1}$, and the last mode $\omega_{n}$ [30].

$$
\left.\begin{array}{l}
\alpha=2 \xi \frac{\omega_{1} \omega_{n}}{\omega_{1+} \omega_{n}} \\
\beta=\frac{2 \xi}{\omega_{1}+\omega_{n}}
\end{array}\right\}
$$

\subsubsection{Soil modelling}

The soil model used in the numerical analysis has dimensions in $3 \mathrm{D}$ of $70 \times 20 \times 10$ $\mathrm{m}^{3}$, where soil is 10 times larger than the structure [31], in order to ensure freefield movement. Soil is represented as a semi-finite domain, which requires the use of dampers at its boundaries to absorb seismic waves and avoid their reflection. The base of the soil is bounded by a rigid bedrock; therefore, soil displacement is disabled, and this allows the seismic load to be taken in terms of displacement time-history [32].

The numerical model discretized the soil domain into finite elements with the dimension $\Delta h$, which allows the propagation of the waves with a maximum frequency $f_{\max }$ based on shear velocity of the soil $V_{s}$. This can be calculated using the following equation:

$$
\Delta h \leq{\frac{V_{s}}{n \cdot f}}_{\max }
$$

Where, $n$ is the number of elements by wavelength which may be adjusted from 5 to 8 [33].

The soil was modelled as solid elements of 08 nodes of a size of $50 \mathrm{~cm}$, with interface refinement for more accurate results. It had a linear behavior with 
Rayleigh-type damping, estimated at 5\% [34]. This type of damping is calculated from the fundamental frequency in the soil $\omega_{1}$ and from the whole number $n$, which multiplies the fundamental frequency. It can be expressed as follows: $\omega_{1}=\pi \cdot V_{s} / 2 D ; \omega_{2}=n . \omega_{1} ; n=\omega_{s} / \omega_{1}$, where $\mathrm{D}$ is soil thickness and $\omega_{s}$ is the fundamental frequency under seismic motion [35].

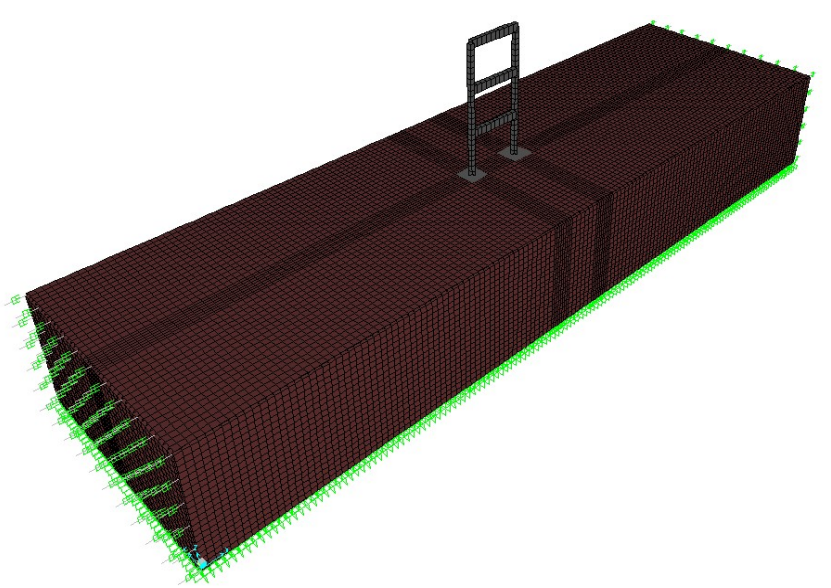

Fig. 13. Modelling soil-structure interaction by finite elements

Displacement in the different frame levels by the finite element method is provided in Table 3.

Table 3. Displacement at the three levels using FEM

\begin{tabular}{|c|c|}
\hline Level & Displacements (cm) \\
\hline 1 & 0.190 \\
\hline 2 & 0.350 \\
\hline 3 & 0.480 \\
\hline
\end{tabular}




\subsubsection{Substructure method}

In this study, a mathematical formula integrating the dynamic impedances of the foundation into the formula of motion vector of three degrees of freedom frame was developed, taking into account soil structure interaction, as shown in Figure 14.

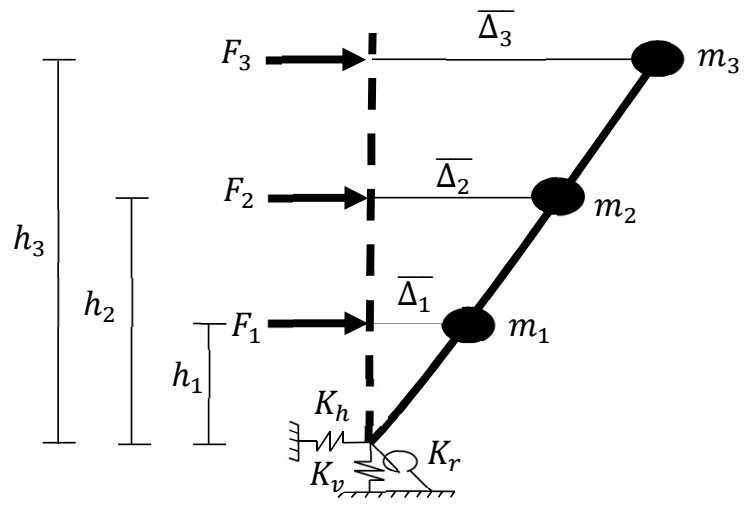

Fig. 14. Three-degrees-of-freedom frame with a flexible base

The displacement vector of the structure is represented as follows:

$$
\left\{\begin{array}{l}
\overline{\Delta_{1}} \\
\overline{\Delta_{2}} \\
\overline{\Delta_{3}}
\end{array}\right\}=\left\{\begin{array}{l}
F_{1} \\
F_{2} \\
F_{3}
\end{array}\right\}\left[\begin{array}{ccc}
\left(K_{1}+K_{2}\right) & -K_{2} & 0 \\
-K_{2} & \left(K_{2}+K_{3}\right) & -K_{3} \\
0 & -K_{3} & K_{3}
\end{array}\right]^{-1}+\frac{1}{K_{h}}\left\{\begin{array}{l}
F_{1} \\
F_{2} \\
F_{3}
\end{array}\right\}+\frac{1}{K_{r}}\left\{\begin{array}{l}
F_{1} \cdot h_{1}^{2} \\
F_{2} \cdot h_{2}^{2} \\
F_{3} \cdot h_{3}^{2}
\end{array}\right\}
$$

Where:

- $\overline{\Delta_{1}} ; \overline{\Delta_{2}} ; \overline{\Delta_{3}}$ : Displacement at each floor;

- $F_{1} ; F_{2} ; F_{3}$ : Static forces on each floor;

- $h_{1} ; h_{2} ; h_{3}$ : Heights of static forces;

- $K_{h} ; K_{r}$ : Respectively represent horizontal translation impedance of the foundation along the $\mathrm{X}$-axis, and rocking impedance around the $\mathrm{Y}$-axis;

- $K_{1} ; K_{2} ; K_{3}$ : Column stiffness on the different floors of the frame:

$$
K_{1}=K_{2}=K_{3}=2 \frac{12 \cdot E_{c} \cdot I_{p}}{l^{3}}
$$


Assuming that: $K_{1}=K_{2}=K_{3}=K$. Then, equation (4.4) becomes:

$$
\left\{\begin{array}{l}
\overline{\Delta_{1}} \\
\overline{\Delta_{2}} \\
\overline{\Delta_{3}}
\end{array}\right\}=\left\{\begin{array}{l}
F_{1} \\
F_{2} \\
F_{3}
\end{array}\right\}\left[\begin{array}{ccc}
2 K & -K & 0 \\
-K & 2 K & -K \\
0 & -K & K
\end{array}\right]^{-1}+\frac{1}{K_{h}}\left\{\begin{array}{l}
F_{1} \\
F_{2} \\
F_{3}
\end{array}\right\}+\frac{1}{K_{r}}\left\{\begin{array}{l}
F_{1} \cdot h_{1}^{2} \\
F_{2} \cdot h_{2}^{2} \\
F_{3} \cdot h_{3}^{2}
\end{array}\right\}
$$

We take stiffness $K$ out of the equation (4.6). The equation becomes:

$$
\left\{\begin{array}{l}
\overline{\Delta_{1}} \\
\overline{\Delta_{2}} \\
\overline{\Delta_{3}}
\end{array}\right\}=\frac{1}{K}\left\{\begin{array}{l}
F_{1} \\
F_{2} \\
F_{3}
\end{array}\right\}\left[\begin{array}{ccc}
2 & -1 & 0 \\
-1 & 2 & -1 \\
0 & -1 & 1
\end{array}\right]^{-1}+\frac{1}{K_{h}}\left\{\begin{array}{l}
F_{1} \\
F_{2} \\
F_{3}
\end{array}\right\}+\frac{1}{K_{r}}\left\{\begin{array}{l}
F_{1} \cdot h_{1}^{2} \\
F_{2} \cdot h_{2}^{2} \\
F_{3} \cdot h_{3}^{2}
\end{array}\right\}
$$

After calculating the inverse matrix of structure stiffness, the displacement vector is as follows:

$$
\left\{\begin{array}{l}
\overline{\Delta_{1}} \\
\overline{\Delta_{2}} \\
\overline{\Delta_{3}}
\end{array}\right\}=\frac{1}{K}\left\{\begin{array}{l}
F_{1} \\
F_{2} \\
F_{3}
\end{array}\right\}\left[\begin{array}{lll}
1 & 1 & 1 \\
1 & 2 & 2 \\
1 & 2 & 3
\end{array}\right]+\frac{1}{K_{h}}\left\{\begin{array}{l}
F_{1} \\
F_{2} \\
F_{3}
\end{array}\right\}+\frac{1}{K_{r}}\left\{\begin{array}{l}
F_{1} \cdot h_{1}^{2} \\
F_{2} \cdot h_{2}^{2} \\
F_{3} \cdot h_{3}^{2}
\end{array}\right\}
$$

Where, $I_{P}$ : Column inertia.

Formula (4.8) provides a good illustration of impedance regarding the calculation of the displacement vector of a three-degrees-of-freedom structure considered as free-field at the base. In our case, the applied force consists of a seismic load variable through time. For our purpose, this force is distributed over the entire frame height in the form of a static force, as shown in Figure 15. 


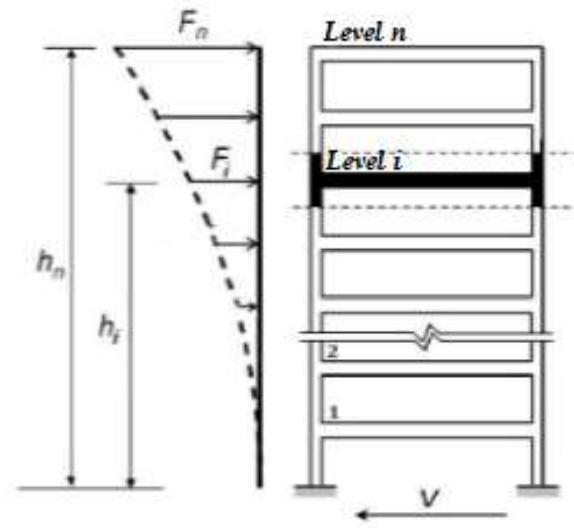

Fig. 15. Vertical distribution of the seismic load [36]

\section{* RPA 2003 code}

According to the RPA 2003 Code [37], the overall seismic force applied to the structure base is expressed by a mathematical formula based on the following parameters: zone acceleration coefficient $(A)$, quality factor $(Q)$, structure behavior coefficient $(R)$, structure total weight $(W)$, and average dynamic amplification factor $(D)$.

The overall seismic force at the base $V$ is given by the following formula:

$$
V=\frac{A \cdot D \cdot Q}{R} W
$$

The total seismic force distribution based on the building height is expressed as follows:

$$
F_{i}=\frac{\left(V-F_{t}\right) W_{i} h_{i}}{\sum_{j=1}^{n} W_{j} h_{j}}
$$

Where, $W_{j}$ and $W_{i}$ : Seismic weight at floor $j$ and $i ; h_{j}$ and $h_{i}$ : Seismic load height at floor $j$ and $i ; F_{t}$ : Concentrated force at the top of the structure: $F_{t}=0.07 T V \leq 0.25 \mathrm{~V}$ or $F_{t}=0$; if $: T \leq 0.7 \mathrm{~s}$.

The fundamental period $T$ is given by the following equation:

$$
T=C_{T} H^{3 / 4}
$$

Where, $H$ : Total structure height; $C_{T}$ : Coefficient based on bracing system and infill type. 
The dynamic amplification factor $D$, based on site category, damping correction factor $\eta$, and structure fundamental period $T$, gives as follows:

$$
D=\left\{\begin{array}{l}
2,5 \eta ; \text { if }: 0 \leq T \leq T_{2} \\
2,5 \eta\left(T_{2} / T\right)^{2 / 3} ; \text { if }: 0 \leq T \leq 3 s \\
2,5 \eta\left(T_{2} / T\right)^{2 / 3}(3 / T)^{5 / 3} ; \text { if }: T \geq 3 s
\end{array}\right.
$$

Where, $T_{1}$ and $T_{2}$ : Characteristic periods associated with site category; $\eta$ : Damping correction factor, given by the formula:

$$
\eta=\sqrt{\frac{7}{2+\xi}}
$$

Where, $\xi(\%)$ : is the critical damping rate based on the constituent materials, structure type, and infill significant.

In our case, the calculation parameters based on RPA2003 are summarized in Table 4, and displacement in each level of the frame, calculated using equation (4.8) and these parameters values, is provided in Table 5.

Table 4. Parameters values based on RPA2003

\begin{tabular}{|c|c|c|c|c|c|c|c|c|c|c|c|}
\hline $\mathbf{A}$ & $\mathbf{R}$ & $\mathbf{Q}$ & $\begin{array}{c}\mathbf{W} \\
(\mathbf{k N})\end{array}$ & $\mathbf{C}_{\mathbf{T}}$ & $\begin{array}{c}\mathbf{T} \\
(\mathbf{s})\end{array}$ & $\begin{array}{c}\mathbf{T}_{\mathbf{1}} \\
(\mathbf{s})\end{array}$ & $\begin{array}{c}\mathbf{T}_{\mathbf{2}} \\
(\mathbf{s})\end{array}$ & $\begin{array}{c}\xi \\
\mathbf{\%}\end{array}$ & $\eta$ & $\mathbf{D}$ & $\begin{array}{c}\mathbf{V} \\
(\mathbf{k N})\end{array}$ \\
\hline 0.25 & 2 & 1.30 & 105 & 0.075 & 0.48 & 0.15 & 0.50 & 7 & 0.88 & 2.20 & 37.62 \\
\hline
\end{tabular}

\begin{tabular}{|c|c|c|c|c|c|c|}
\hline Level & $\begin{array}{c}\mathbf{W}_{\mathbf{i}} \\
(\mathbf{k N})\end{array}$ & $\begin{array}{c}\mathbf{h}_{\mathbf{i}} \\
\mathbf{( m )}\end{array}$ & $\begin{array}{c}\mathbf{W}_{\mathbf{i} . \mathbf{h}_{\mathbf{i}}} \\
(\mathbf{k N} . \mathbf{m})\end{array}$ & $\frac{W_{i} h_{i}}{\sum_{j=1}^{3} W_{j} h_{j}}$ & $\begin{array}{c}\mathbf{F}_{\mathbf{i}} \\
(\mathbf{k N})\end{array}$ & $\begin{array}{c}\overline{\Delta_{i}} \\
\mathbf{( c m )}\end{array}$ \\
\hline
\end{tabular}




\begin{tabular}{|l|c|c|c|c|c|c|}
\hline 1 & 35 & 4 & 140 & 0.167 & 06.270 & 0.189 \\
\hline 2 & 35 & 8 & 280 & 0.333 & 12.540 & 0.349 \\
\hline 3 & 35 & 12 & 420 & 0.500 & 18.810 & 0.450 \\
\hline
\end{tabular}

Table 5. Displacement in the three levels of the frame based on RPA2003

\section{* UBC97 code}

According to UBC97 (Uniform Building Code 97) [38], seismic force is laterally distributed over the height of the structure at each level. It is determined using the following formula:

$$
F_{x}=\frac{\left(V-F_{t}\right) W_{x} h_{x}}{\sum_{i=1}^{n} W_{i} h_{i}}
$$

Where, $W_{x}$ and $W_{i}$ : Seismic weight at floor $x$ and $i ; h_{x}$ and $h_{i}$ : Seismic load height at floor $x$ and $i$; $V$ : Base shear specified by the formula:

$$
V=C_{S} \cdot W
$$

Where, $W$ : Total seismic weights; $C_{S}$ : Seismic response coefficient:

$$
C_{S}=\frac{S_{D S}}{R / I_{e}}
$$

Where, $I_{e}$ : Seismic importance factor ensures a seismic force of a superior design for larger structures. The values of $I_{e}$ mainly related to earthquake resistance design category divided into four occupational categories: $I_{e}=1$ for category I and II; $I_{e}=1.25$ for category III; $I_{e}=1.5$ for category IV; $R$ : Response modification factor, whose values generally range from 1 for the systems incapable of having a ductile response to 8 for the systems capable of responding in a highly ductile manner; $S_{D S}$ : Acceleration response for short periods:

$$
S_{D S}=\frac{2}{3} F_{a} S_{S}
$$

Where, $S_{S}$ : Spectral response acceleration for short periods; $F_{a}$ : Coefficient linked to site class indicates site soil related amplification effects on soil shaking energy for short (high frequency) and long periods (low frequency). 
In our case, calculation parameters based on UBC97 are summarized in Table 6, and displacement at each level of the frame calculated using the equation (4.8) and these parameter values, is provided in Table 7.

Table 6. Parameters values based on UBC97

\begin{tabular}{|c|c|c|c|c|c|c|c|}
\hline $\mathbf{F}_{\mathbf{a}}$ & $\mathbf{S} \mathbf{s}$ & $\mathbf{S}_{\mathbf{D s}}$ & $\mathbf{R}$ & $\mathbf{I}_{\mathbf{e}}$ & $\mathbf{C s}$ & $\mathbf{W}(\mathbf{k N )}$ & $\mathbf{V}(\mathbf{k N})$ \\
\hline 1.2 & 0.75 & 0.6 & 2 & 1.25 & 0.375 & 105 & 39.375 \\
\hline
\end{tabular}

Table 7. Displacement in the three levels of the frame based on UBC97

\begin{tabular}{|c|c|c|c|c|c|c|}
\hline Level & $\mathbf{W}_{\mathbf{i}}(\mathbf{k N})$ & $\mathbf{h}_{\mathbf{i}}(\mathbf{m})$ & $\mathbf{W}_{\mathbf{i} . \mathbf{h}_{\mathbf{i}}(\mathbf{k N} . \mathbf{m})}$ & $\mathbf{C}_{\mathbf{v i}}$ & $\mathbf{F}_{\mathbf{i}}=\mathbf{C}_{\mathbf{v i}} \cdot \mathbf{V}(\mathbf{k N})$ & $\overline{\Delta_{i}}(\mathbf{c m})$ \\
\hline 1 & 35 & 4 & 140 & 0.167 & 06.562 & 0.198 \\
\hline 2 & 35 & 8 & 280 & 0.333 & 13.125 & 0.365 \\
\hline 3 & 35 & 12 & 420 & 0.500 & 19.687 & 0.471 \\
\hline
\end{tabular}

The two codes RPA 2003 and UBC 97 allow the distribution of the seismic force over the structure using a method known as "the equivalent static method". Each code has special calculation parameters depending on the type of the site and the structure being analyzed, in order to determine the value of the seismic load at the base and to distribute it over the structure height. Both codes gave close displacement values in the three levels of the frame, validating the efficiency of each code in the seismic analysis.

Displacement at third level (top of the frame) based on both codes is considered to be at its maximum, which is very close to what has been found using the finite element method (see Figure 16). This shows the accuracy of the method used to calculate structure displacement under seismic excitation. 


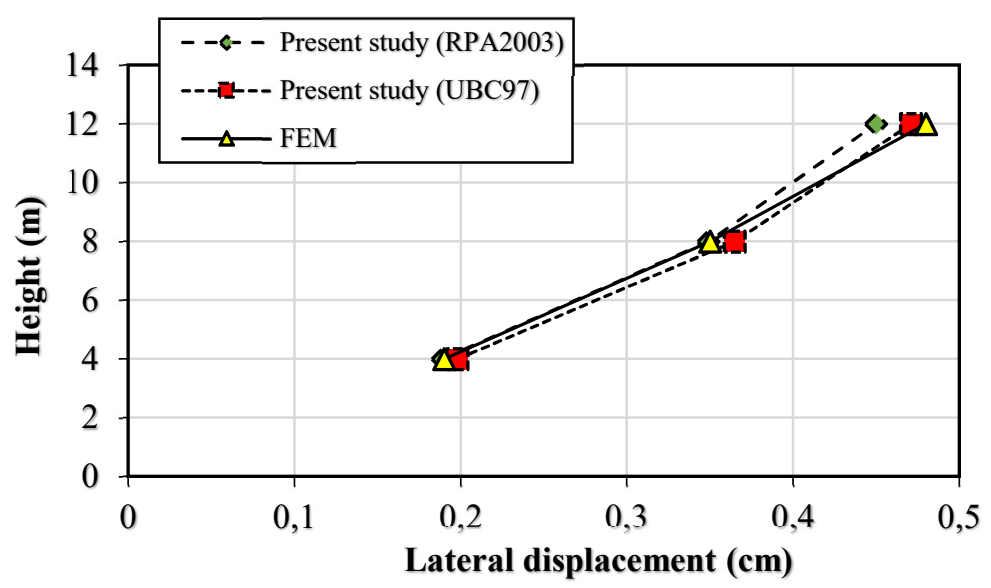

Fig. 16. Presentation of lateral displacement values using the two methods

The distribution of the seismic charge found in the linear soil on the three levels of the frame by the method mentioned above can cause the lateral displacement of the mass of the corresponding floor $m_{i}$. This displacement varied linearly with the force applied by a slope $K_{i}$, as presented in Figure 17. We can see that there is a proportionality between the applied force and the appropriate displacement.

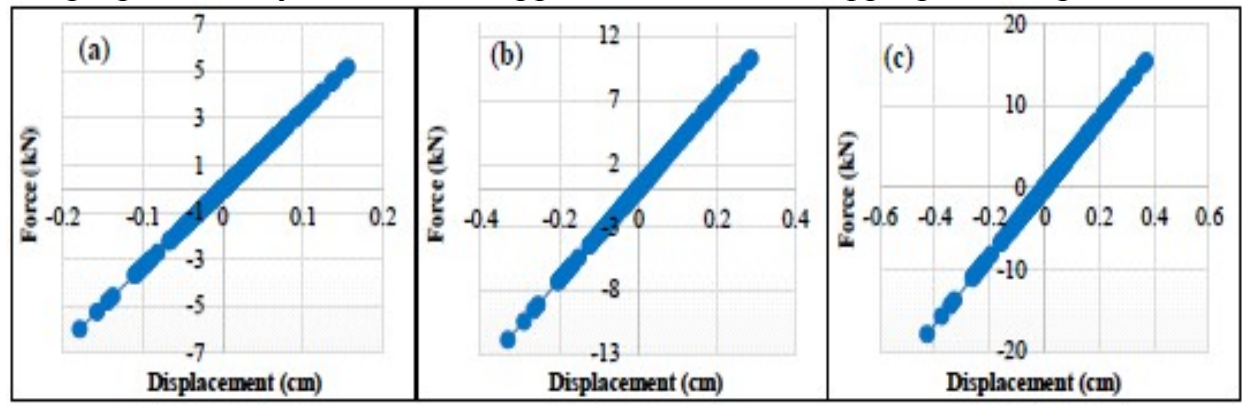

Fig. 17. Linear behavior of the frame in the three levels: (a) first level (b) second level (c) third level

\subsection{Nonlinearity effect on the response of the structure}

It is important to take into account the effect of damping of the soil in the dynamic analysis of foundations, which caused a decrease of dimensionless deflection [39]. In this part of the study, we tried to justify the effect of soil behavior on the response of a three-degrees-of-freedom frame taking into consideration the effect of the nonlinearity of the soil. It is well known that the rheological models are the only ones to have an influence on a structure's lateral responses in the horizontal direction and on its rocking [40], as shown in Figure 18. 


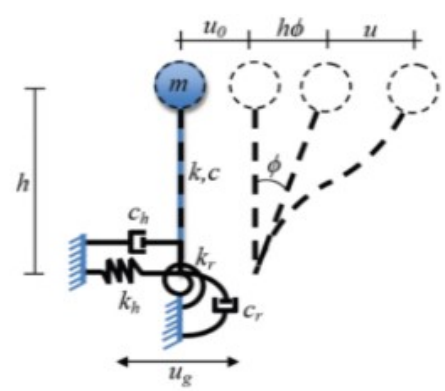

Fig. 18. Displacement components of a flexible base structure [41]

Under dynamic loading, the foundation response must be strictly represented using a « springs + dampers » type analogical model (Kelvin-Voigt) in which the characteristics $K(\omega)$ and $C(\omega)$ depend on loading frequency, and these characteristics receptively constitute the real and the imaginary part of the dynamic impedances of the foundation. These two terms are given the physical meaning of a spring and a damper with the following characteristics:

$$
\left.\begin{array}{l}
K=K_{S} K_{1}(\omega) \\
C=\frac{K_{S} r_{0} C_{1}(\omega)}{V_{S}}
\end{array}\right\}
$$

Including damping in the calculation of the effect of the soil on the response of structure makes it possible to add another parameter to the elastic formula of frame lateral displacement. This parameter $\overline{\Delta_{c}}$, in terms of time $\Delta T$, is associated with the displacement resulting from the horizontal damper $C_{h}$ and rocking damper $C_{r}$ as follows:

$$
\overline{\Delta_{c}}=\left(\frac{1}{C_{h}}+\frac{h^{2}}{C_{r}}\right) F . \Delta T
$$

The displacements in the three levels of the structure with and without damping are presented in the Figures 19, 20, and 21. 


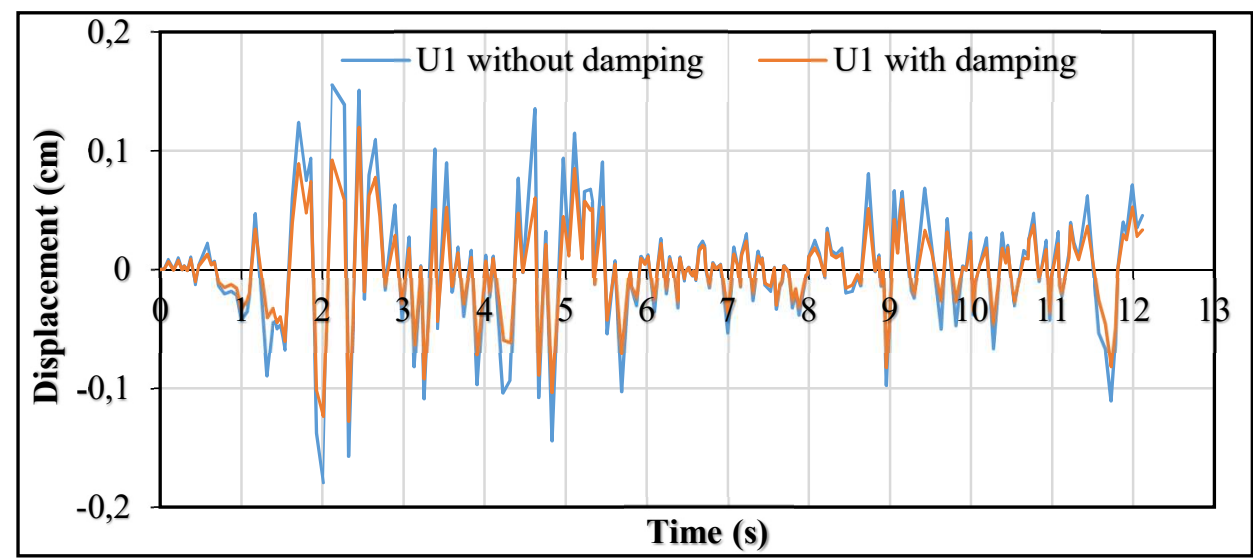

Fig. 19. Effect of damping on the lateral displacement at the first level of the frame

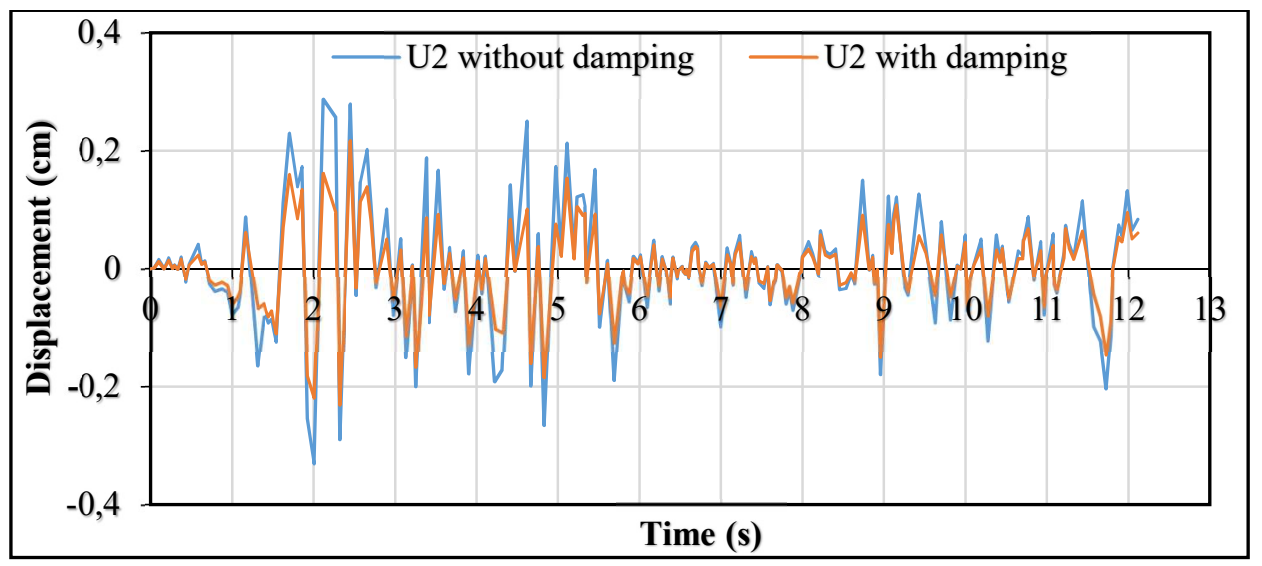

Fig. 20. Effect of damping on the lateral displacement at the second level of the frame 


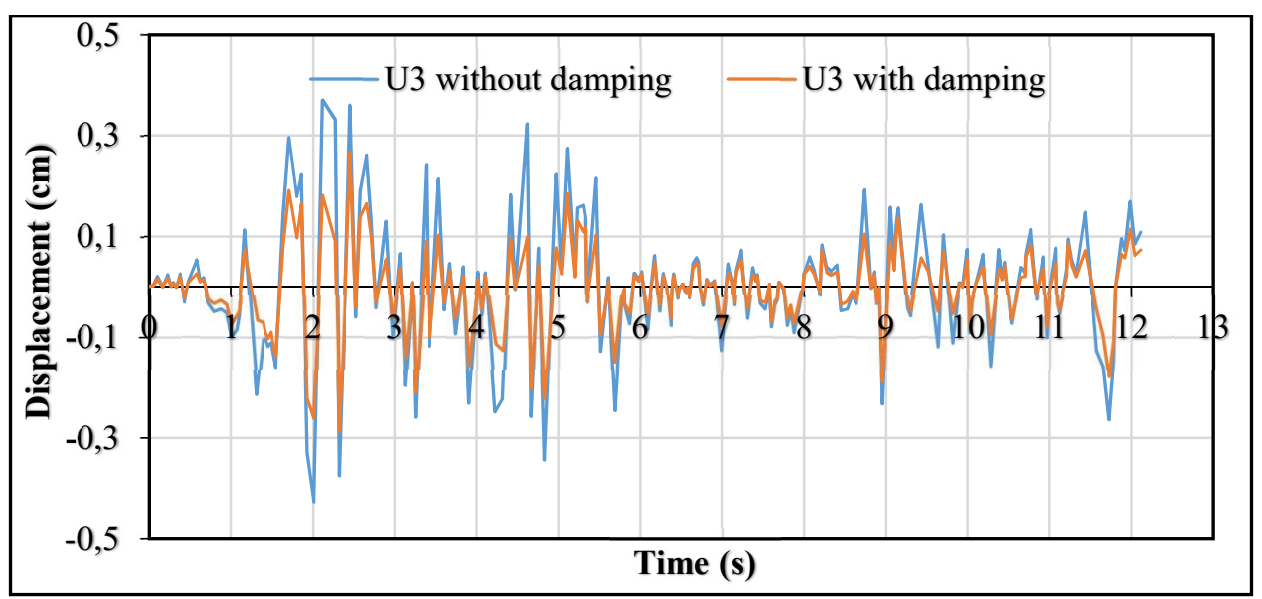

Fig. 21. Effect of damping on the lateral displacement at the third level of the frame

The effect of nonlinearity on the frame displacement is shown in Figures 19 to 21, minimizing displacement at the three levels of the frame. This effect is estimated at $31.28 \%$ at the first level, $33.83 \%$ at the second level, and $39.53 \%$ at the third level, thereby confirming that the impact of damping increases with height [42].

The effect of damping on the frame behavior is illustrated by the change in the linearity of the curve $F=f(\bar{\Delta})$ at the three levels of the frame (see Figure 22). It could therefore be concluded that the response of the structure founded on a nonlinear soil exhibits a certain ductility under seismic loading. It is worthy of note, in this regard, that taking into account the nonlinearity of the interaction between the soil and the structure helps to limit the seismic action transmitted into the latter [43] 

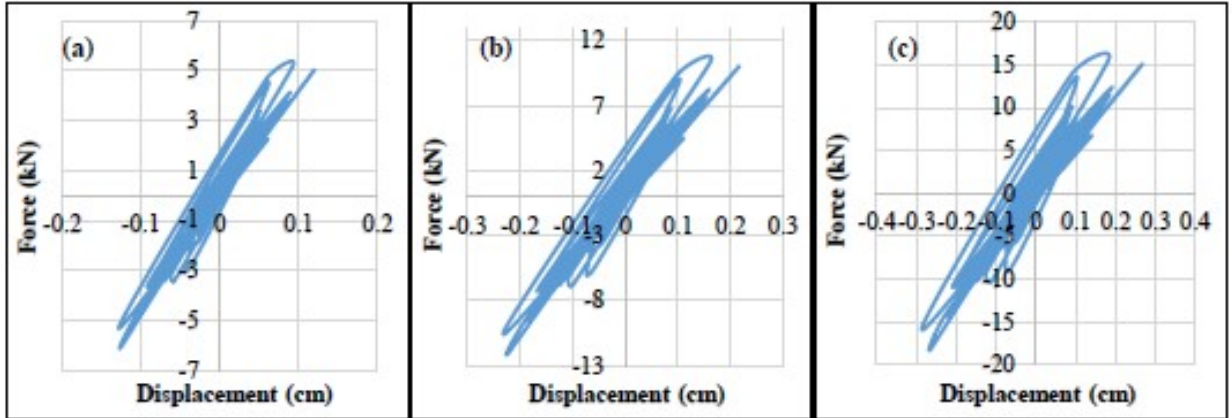

Fig. 22. The effect of damping on the frame behavior at the three levels: (a) first level (b) second level (c) third level

\subsection{Parametric study}

This part of the study deals with the effect of soil densification and the change of foundation radius on their dynamic response whose impedance functions were calculated using the CONAN program. It also deals with the effect of dynamic impedance on structure displacement using the substructure method previously proposed.

\subsubsection{Effect of soil densification on structure response}

Compaction techniques (also known as mass densification techniques) become widely used in significantly improving some soil characteristics [44, 45]. This technique particularly effects shear wave velocity $V_{s}$ as well as soil density $\rho$, and causes a change in the class of the soil under consideration. The parameters used in changing soil class according to UBC97 are provided in Table 8.

Table 8. Parameters of soil before and after compaction

\begin{tabular}{|c|c|c|c|}
\hline Condition of soil & Class of soil & $V_{S}(\mathbf{m} / \mathbf{s})$ & $\rho\left(\mathbf{k N} / \mathbf{m}^{3}\right)$ \\
\hline Before compaction & $\mathrm{E}$ & 170 & 18 \\
\hline After compaction & $\mathrm{D}$ & 185 & 20 \\
\hline Before compaction & $\mathrm{D}$ & 300 & 20 \\
\hline After compaction & $\mathrm{C}$ & 365 & 22 \\
\hline
\end{tabular}



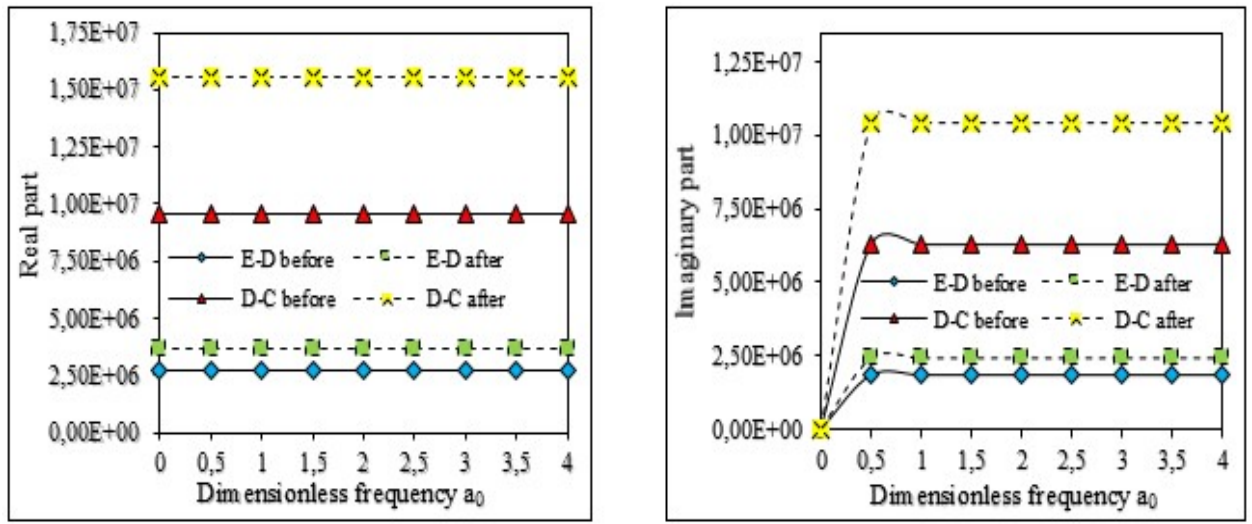

Fig. 23. Effect of soil densification on horizontal impedance
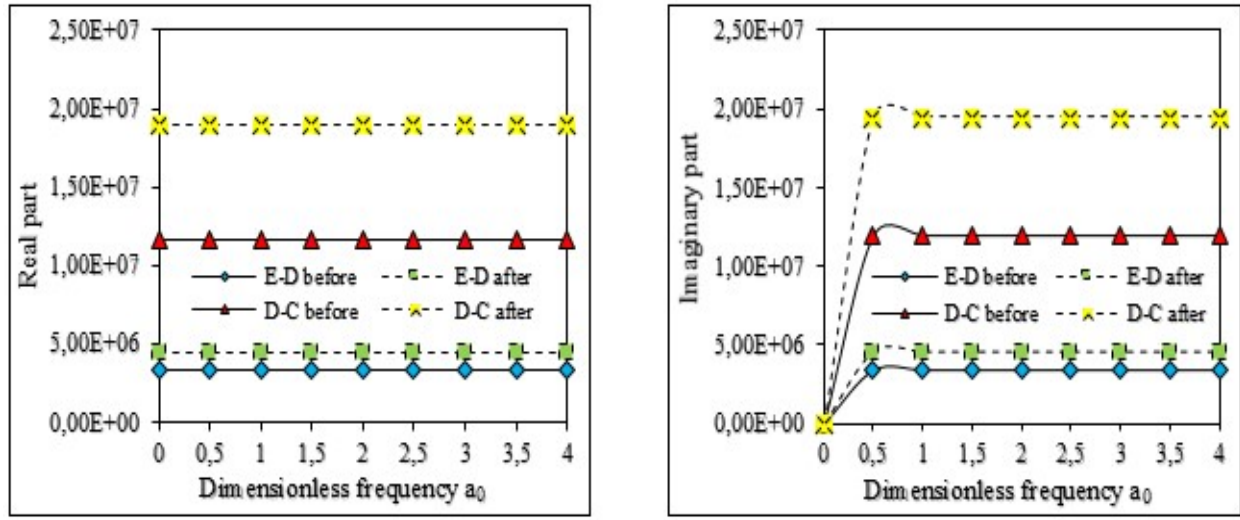

Fig. 24. Effect of soil densification on vertical impedance
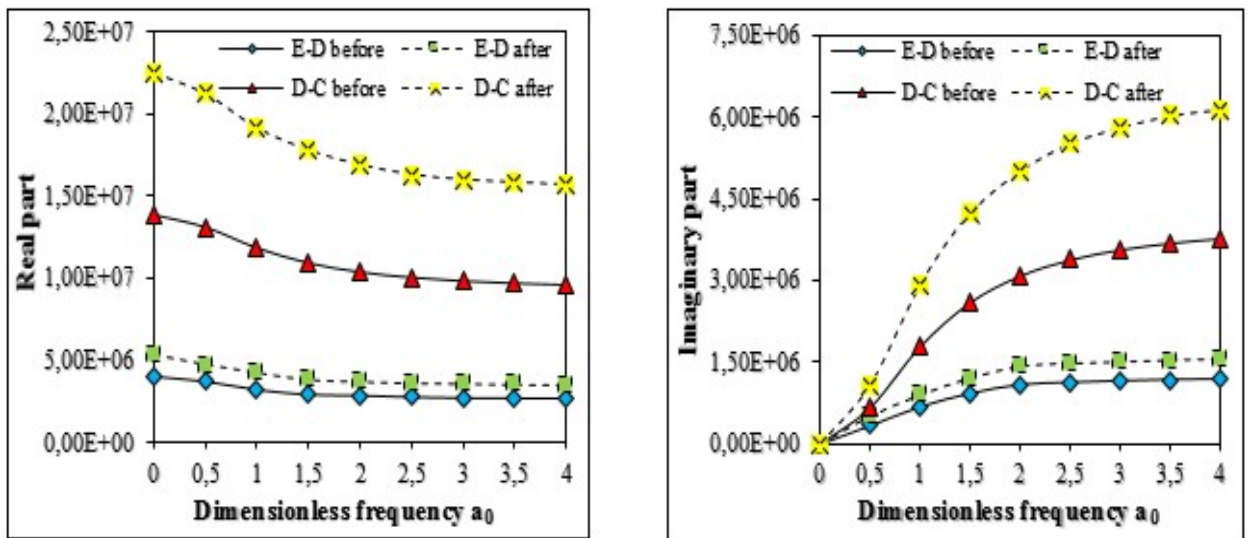

Fig. 25. Effect of soil densification on torsional impedance 

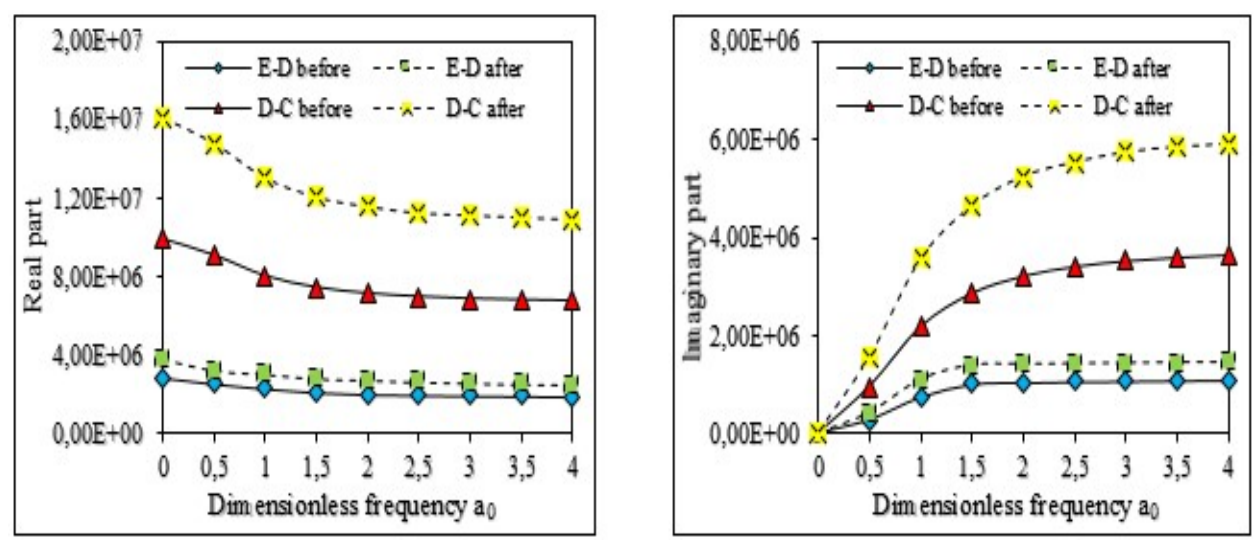

Fig. 26. Effect of soil densification on rocking impedance

Figures 23 to 26 show the effects of soil improvement by densification on the variation of dynamic impedances based on the dimensionless frequency. The results obtained show the efficiency of soil densification; both the stiffness and damping are strongly affected by the latter. A considerable increase in stiffness and damping was noticed for all dynamic impedances. Therefore, compaction has a direct influence on soil damping and stiffness in a proportionate manner. The effect of soil densification on structure response is given in Table 9.

Table 9. Displacement values at the three levels of the structure before and after densification of the supporting soil

\begin{tabular}{|c|c|c|c|c|c|}
\hline \multicolumn{2}{|c|}{ Condition of soil } & $\begin{array}{c}\text { E-D } \\
\text { before }\end{array}$ & $\begin{array}{c}\text { E-D } \\
\text { after }\end{array}$ & $\begin{array}{c}\text { D-C } \\
\text { before }\end{array}$ & $\begin{array}{c}\text { D-C } \\
\text { after }\end{array}$ \\
\hline \multirow{2}{*}{$\begin{array}{c}\text { Displacement at } \\
\text { level 1 }(\mathrm{cm})\end{array}$} & RPA2003 & 0.243 & 0.242 & 0.189 & 0.188 \\
\cline { 2 - 6 } & UBC97 & 0.210 & 0.200 & 0.198 & 0.181 \\
\hline $\begin{array}{c}\text { Displacement at } \\
\text { level 2 }(\mathrm{cm})\end{array}$ & RPA2003 & 0.456 & 0.453 & 0.349 & 0.347 \\
\cline { 2 - 6 } & UBC97 & 0.374 & 0.370 & 0.365 & 0.333 \\
\hline $\begin{array}{c}\text { Displacement at } \\
\text { level 3 }(\mathrm{cm})\end{array}$ & RPA2003 & 0.610 & 0.599 & 0.450 & 0.446 \\
\cline { 2 - 6 } & UBC97 & 0.500 & 0.490 & 0.471 & 0.428 \\
\hline
\end{tabular}

Densification of the soil by compaction causes the decrease of lateral displacement of the structure in the three levels in an increasing way. According to Table 9, this effect varied according to the following points:

- It is more important in the third level of the frame. Therefore, we can see that the effect of compaction of soil on the lateral displacement of the structure is more important according to the height of the latter.

- It is more important in D-C soil, better than in E-D soil, because of the difference in shear wave velocity found before and after compaction, which is considered greater in the D-C soil type.

- It is more important in the UBC97 norm than in the RPA2003, because the former allows classification of the soils studied before and after compaction, according to their shear wave velocity at two sites that have calculation 
parameters that differ (E-D before: class E; E-D after: class D; and D-C before: class D; D-C after: class C). On the other hand, the latter classified the soils studied before and after compaction on the same site (E-D before and after: class $\mathrm{S}_{4}$; D-C before and after: class $\mathrm{S}_{3}$ ), that is to say, the soil before and after compaction has the same calculation parameters. Therefore, the difference in displacements does not appear significant.

\subsubsection{Effect of foundation radius on the structure response}

In this section, foundation radius will be changed from $1.13 \mathrm{~m}$ to $0.85 \mathrm{~m}$ and $0.56 \mathrm{~m}$. Figures 27 to 30 present the effect of foundation radius in the variation of dynamics impedance for the four degrees of freedom using the same calculation methods of impedance functions previously presented.
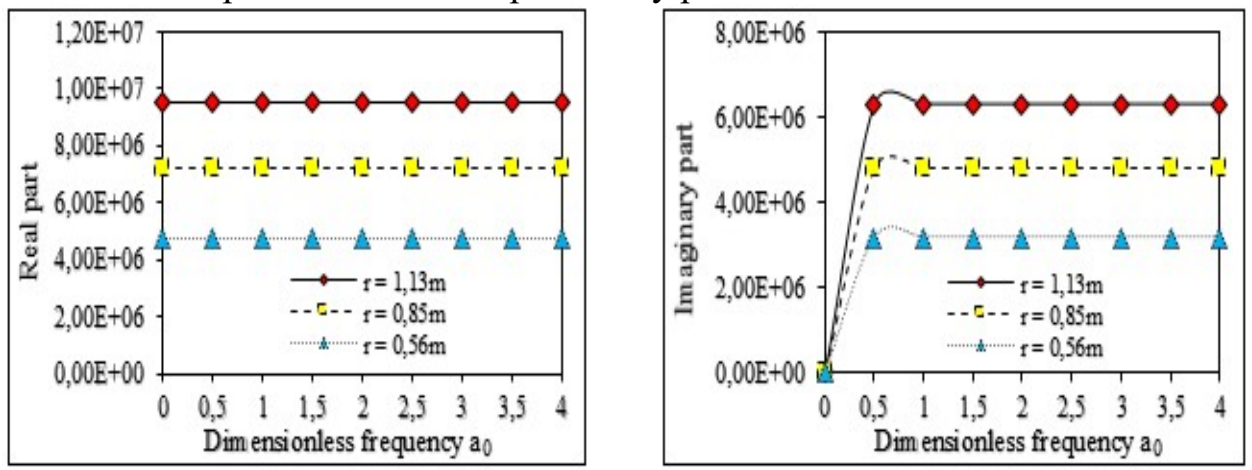

Fig. 27. Effect of foundation radius variation on the values of horizontal impedance 

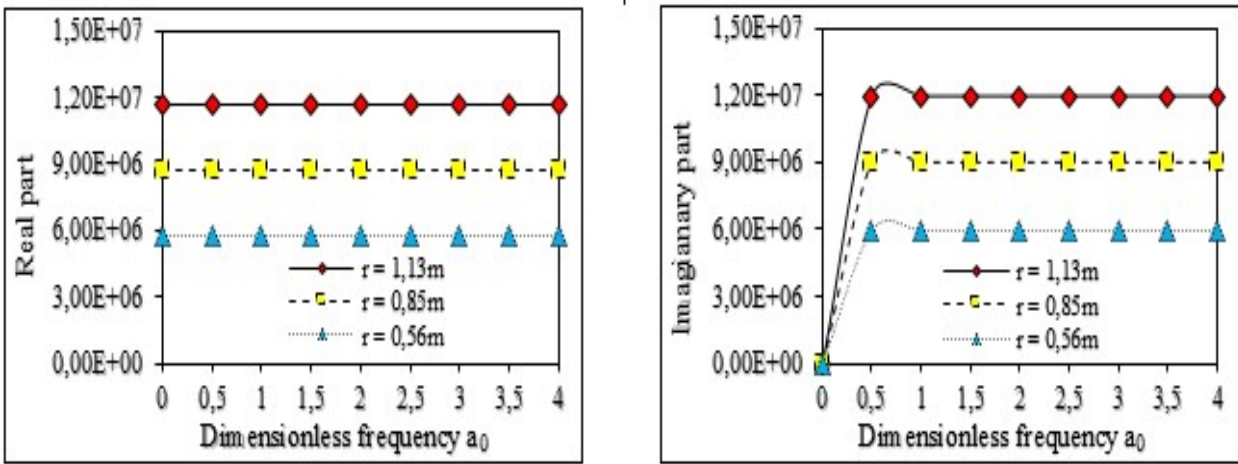

Fig. 28. Effect of foundation radius variation on the values of vertical impedance
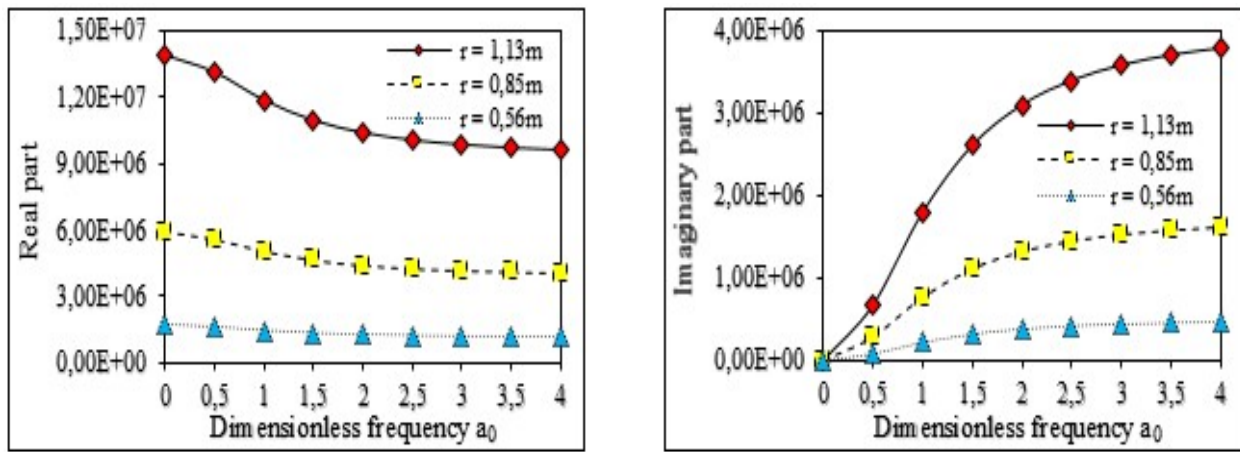

Fig. 29. Effect of foundation radius variation on the values of torsional impedance
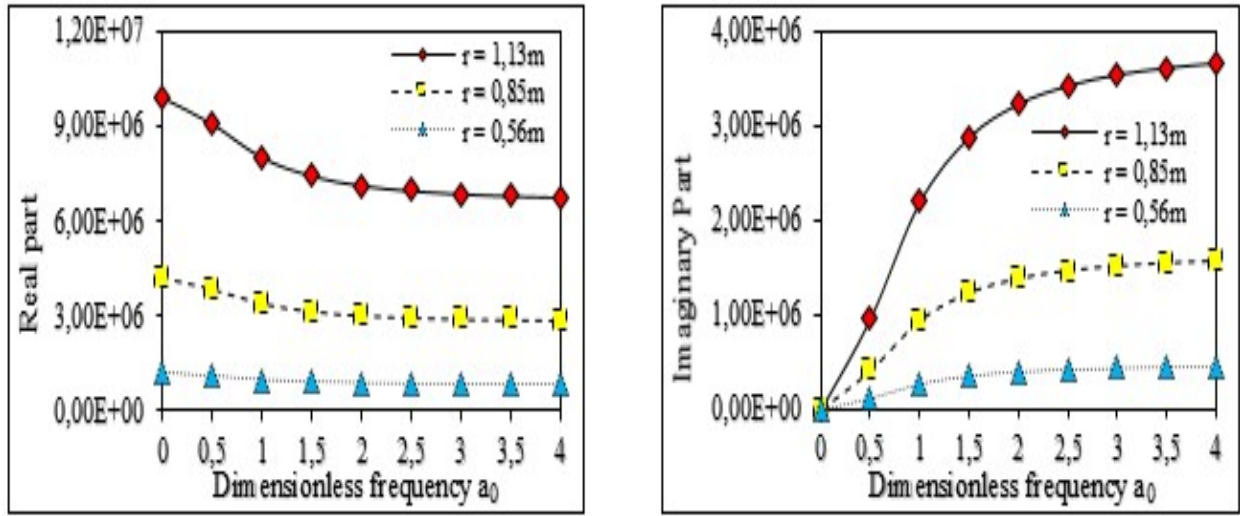

Fig. 30. Effect of foundation radius variation on the values of rocking impedance

The results obtained show that foundation radius (foundation geometry) is an important parameter in infrastructure design. Impedance functions in terms of stiffness and damping are strongly influenced by foundation radius; a considerable 
decrease in stiffness and damping was marked in Figures 27 to 30 for the four degrees of freedom. The decrease in stiffness and damping is proportionate to the decrease in foundation radius. The effect of foundation radius on structure response is given in Table 10.

Table 10. Displacement values at the three levels of the structure depending on the variation of foundation radius

\begin{tabular}{|c|c|c|c|c|}
\hline \multicolumn{2}{|c|}{ Equivalent radius } & $\mathbf{1 . 1 3} \mathbf{~ m}$ & $\mathbf{0 . 8 5} \mathbf{~ m}$ & $\mathbf{0 . 5 6} \mathbf{~ m}$ \\
\hline $\begin{array}{c}\text { Displacement at level 1 } \\
(\mathrm{cm})\end{array}$ & RPA 2003 & 0.189 & 0.189 & 0.190 \\
\cline { 2 - 5 } & UBC97 & 0.198 & 0.198 & 0.199 \\
\hline $\begin{array}{c}\text { Displacement at level 2 } \\
(\mathrm{cm})\end{array}$ & RPA 2003 & 0.349 & 0.352 & 0.362 \\
\cline { 2 - 5 } & UBC97 & 0.365 & 0.368 & 0.379 \\
\hline $\begin{array}{c}\text { Displacement at level 3 } \\
(\mathrm{cm})\end{array}$ & RPA 2003 & 0.450 & 0.461 & 0.495 \\
\cline { 2 - 5 } & UBC97 & 0.471 & 0.483 & 0.518 \\
\hline
\end{tabular}

The effects of foundation design on the response of the structure are shown in Table 10, in particular at the third level, which demonstrate the existence of an inverse proportionality between structure displacement and increasing foundation radius.

\section{CONCLUSIONS}

The work presented attempted to illustrate the effect of soil on the response of a multistorey frame through dynamic impedance in both linear and nonlinear cases by developing a substructure method in which the horizontal and rocking dynamic impedances of the foundation are included in motion vector of the structure. The calculation was justified by a finite element method and made under the variation of the different parameters such as shear wave velocity, soil density, and 
foundation dimensions. Maximum displacement values related to the height of the frame are summarized in Figure 31.

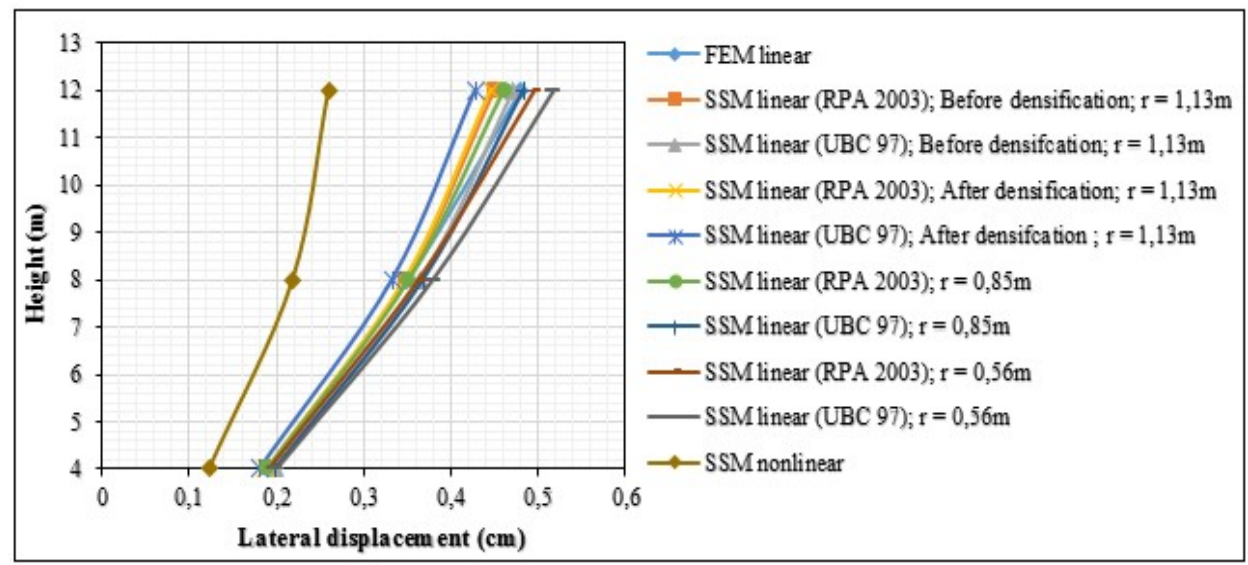

Fig. 31. Maximum displacements in the frame

The study was very extensive, starting with the calculation of dynamic impedances through to the calculation of the frame displacement at the three levels, under different soil and structure parameters. In this regard, the following points were determined:

- The different dynamic impedance calculation methods were presented for the translational and rotational degrees of freedom. First, this impedance function was illustrated by mathematically developing the sum of forces applied to the foundation in the different directions. Then, the formula of the force applied was derived. This force is mainly related to the displacement imposed by the dynamic stiffness. Then, a numerical calculation tool was presented and used to easily calculate the dynamic impedances and to determine their variation according to increasing the dimensionless frequency.

- The calculation of dynamic impedances allowed us to demonstrate soil effects on the response of structures considered to be free at the base. This is shown by the formula of motion vector of a three-degrees-of-freedom structure with a flexible base. In fact, the substructure method uses these impedances to determine spring stiffness and damper values in the different degrees of freedom.

- The developed substructure method is static based on the equivalent static method, which allows determining of the static forces in each level of the frame using two codes; RPA2003 and UBC97. The results, as a function of maximum lateral displacement given by the finite element method, and their comparison with those given by the presented substructure method, which is based on the 
cone model, make it possible to appreciate the importance, precision, and ease of the latter in practice and also in the calculation of displacement of structures found in seismic zones.

- Soil damping played an important role in the earthquake resistance of the superstructure, by minimizing its displacement and changing its behavior so it could have certain ductility under seismic excitation.

- The effects of soil densification on structural behavior were examined through the evaluation of impedance functions calculated using the cone method for the four degrees of freedom. A considerable increase in stiffness and damping was noticed for all dynamic impedances. Therefore, compaction has a direct influence on soil damping and stiffness in a proportionate manner. This causes a decrease in motion of the structure being studied.

- The impact of soil type change on the design of a construction after densification of the soil by means of compaction techniques could be significant and beneficial in terms of reduction of load range, therefore, it could be an economic asset.

- Impedance functions are heavily influenced by foundation radius. A decrease in the latter leads to a decrease in stiffness and damping, which ultimately causes an increase in displacement of the structure being studied.

\section{REFERENCES}

1. Medina, C, Aznárez, JJ, Padrón, LA and Maeso, O 2013. Effects of soilstructure interaction on the dynamic properties and seismic response of piled structures. Soil Dynamics and Earthquake Engineering 53, 160-175.

2. Lamb, EH 1904. On the propagation of tremors over the surface of an elastic solid. Philosophical transactions of the royal society London, A, Vol. 203, Issue 359-371, 1-42.

3. Reissner, E 1936. Stationary, axially symmetrical of a homogeneous elastic half-space excited by a shut-telling mass (Stationare, axialsymmetrische, durch eine shut-telnde masse erregte shwimgugen eines homogenen elastischen halbraumesn). Ing. Archives, 7 (381). 
4. Sung, TY 1953. Vibration in semi-infinite solid due to periodic surface loading. PhD thesis, University of Harvard, USA.

5. Lysmer, J 1965. Vertical motions of rigid footings. PhD thesis, Department of Civil Engineering, University of Michigan, USA.

6. Cevaer, F 1993. Soil-structure interaction. Modelling of Impedance functions (Interaction sol-structure. Modélisation des fonctions d'impédance). $\mathrm{PhD}$ thesis, Department of Civil Engineering, University of Nantes, France.

7. Gazetas, G 1991. Formulas and charts for impedance of surface and embedded foundations. Journal of Geotechnical Engineering 117 (9), 13631381.

8. Bratosin, D and Sireteanu, T 2002. Hysteretic damping modelling by nonlinear kelvin-voigt model. In Proceedings of the Romanian Academy, August, Publishing House of the Rumanian Academy, Series A, 3 (3), 1-6.

9. Xianjian, Y and Bei, J 1998. Radiation Damping of Soil-Foundations Interaction Systems. In $4^{\text {th }}$ International Conference on Case Histories in Geotechnical Engineering, Missouri University, Rolla, USA, March, 8-15, 1120-1124.

10. Aydin, E, Ozturk, B, Bogdanovic, A and Farsangi, EN 2020. Influence of soil-structure interaction (SSI) on optimal design of passive damping devices. Structures 28, 847-862.

11. Hamidi, B, Nikraz, H and Varaksin, S 2009. A review of impact oriented ground improvement techniques. Australian Geomechanics Journal 44 (2), 17-24.

12. Edip, K, Garevski, M, Sheshov, V and Bojadjieva, J 2017. Boundary effects in simulation of soil-structure interaction problems. Soil Mechanics and Foundation Engineering 54 (4), 239-243.

13. Jaber, L, Temsah, Y, Hage Chehade, F and El-Mossallamy, Y 2018. Effect of Soil-Structure Interaction Constitutive Models on Dynamic Response of Multi-Story Buildings. Journal of Engineering Science and Technology Review 11(3), 56-60.

14. Ada, M and Ayvaz, Y 2019. The Structure-Soil-Structure Interaction Effects on the Response of the Neighbouring Frame Structures. Latin American Journal of Solids and Structures 16 (8), 1-19.

15. Edip, K, Bogdanovic, A, Stojmanovska, M, Poposka, A and Farsangi, EN 2020. A new approach in simulation of soil-structure interaction problems including damper effects. International Journal of Earthquake and Impact Engineering 3 (1), 1-14.

16. Okyay, US, Billion, P, Daniel, D, Vandeputte, D and Courtois, A 2012. Impedance Functions of Slab Foundations with Rigid Piles. Journal of Geotechnical and Geological Engineering 30 (4), 1013-1024.

17. Chung, IL and Liou, GS 2013 Calculation of impedances for axial symmetric 
foundation embedded in half-space medium using solutions for one layer stratum. Solids and Structures 10 (6), 1225-1241.

18. Messioud, S, Dias, D, Okyay, US and Sbartai, B 2016. Dynamic Response of Pile Reinforced Soils and Piled Foundations. Geotechnical and Geological Engineering 34 (3), 789-805.

19. Jahangir, K, Azadeh, A and Mahredad, K 2017. Seismic evaluation of soilfoundation-structure: Direct and Cone model. Journal of Earthquakes and Structures 12 (2), 251-262.

20. Karatzia, X, Mylonakis, G and Bouckovalas, G 2017. $3 D$ dynamic impedances of surface footings on liquefiable soil: equivalent linear approach. In $16^{\text {th }}$ World Conference on Earthquake Engineering, Santiago, Chile, January, 09-13, 1-12.

21. Wolf, JP and Deeks, AJ 2004. Foundation vibration analysis: a strength-ofmaterials approach. Oxford, UK, Elsevier, 215 pages.

22. $\mathrm{Hu}, \mathrm{CY}, \mathrm{Chen}, \mathrm{QJ}, \mathrm{Xiong}, \mathrm{QQ}$ and Xu, QY 2011. Simplified calculation method for impedance function of embedded block foundation. Vibration and Shock 30 (5), 252-256.

23. Guellil, M 2013. Stochastic modeling of the dynamic soil-structure interaction (Modélisation stochastique de l'interaction dynamique solstructure). Journée d'étude sur la Dynamique des Sols et l'Interaction SolStructure, Chlef, Algeria, November, 07, 27-30.

24. Aldimashki, MM, Brownjohn, J and Bhattacharya, S 2014. Experimental and analytical study of seismic soil pile structure interaction in layered soil half space. Earthquake Engineering 18 (5), 655-673.

25. Najar, BA and Najar, IA 2016. Comparative Seismic Analysis of El Centro and Japan Earthquakes using Response Spectra Method. International Journal of Current Engineering and Technology 6 (5), 1859-1864.

26. Tabatabaiefar, HR and Clifton, T 2016. Significance of considering soilstructure interaction effects on seismic design of unbraced building frames resting on soft soils. Australian Geomechanics journal 51 (1), 55-64.

27. Gu, Q, Liu, Y, Li, Y and Lin, C 2018. Finite element response sensitivity analysis of three-dimensional soil-foundation-structure interaction (SFSI) 
systems. Earthquake Engineering and Engineering Vibration, 17 (3), 555566.

28. Takabatake, H, Kitada, Y, Takewaki, I and Kishida, A 2019. Analysis Considering Soil Structure Interaction In: Simplified Dynamic Analysis of High-Rise Buildings, Chapter 8, Singapore, Springer, 211-239.

29. Elias, S and Matsagar, V 2017. Effectiveness of tuned mass dampers in seismic response control of isolated bridges including soil-structure interaction. Latin American Journal of Solids and Structures 14 (13), 23242341.

30. Mendes, MV, Vieira Ribeiro, PM and Pedroso, LJ 2019. Effects of soilstructure interaction in seismic analysis of buildings with multiple pressurized tuned liquid column dampers. Latin American Journal of Solids and Structures 16 (8), 1-21.

31. Zhai, P, Zhao, P, Lu, L, Ye, C and Xiong, F 2019. Seismic Fragility Analysis of Buildings Based on Double-Parameter Damage Models considering SoilStructure Interaction. Advances in Materials Science and Engineering 2019 , $1-13$.

32. Bolisetti, C and Whittaker, AS 2015. Site response, soil-structure interaction and structure-soil-structure interaction for performance assessment of buildings and nuclear structures. MCEER, University of Buffalo, New York, USA, 388 pages.

33. Kuhlemeyer, RL and Lysmer, J 1973. Finite Element Method Accuracy for Wave Propagation Problems. Journal of the Soil Dynamics Division 99 (5), 421-427.

34. Amorosi, A, Boldini, D and Di-Lernia, A 2017. Dynamic soil-structure interaction: a three dimensional numerical approach and its application to the Lotung case study. Computers and Geotechnics 90, 34-54.

35. Hudson, M, Idriss, IM and Bekaie, M 1994. QUAD4M - A Computer Program to Evaluate the Seismic Response of Soil Structures Using Finite Element Procedures Incorporating a Compliant Base. Center for Geotechnical Modeling, University of California, USA, 72 pages.

36. NEHRP 2015. Recommended Seismic Provisions for Seismic Regulation of Buildings and Other Structures. FEMA P -1051, prepared for FEMA by the Building Seismic Safety Council. Federal Emergency Management Agency, Washington, D.C. USA.

37. RPA 2003. The seismic code of Algeria. DTR B C 2 48, National Center for Applied Research in Earthquake Engineering, Algiers, Algeria.

38. UBC 1997. Uniform Building Code. International Conference of Building Officials, Whittier, California, USA.

39. Gibigaye, M, Yabi, C P, Alloba, E I, Farsangi, EN and Degan, G 2020. Hybrid DSC-T/ $\beta$-Newmark Method for Dynamic Response Analysis of 
Isotropic Thin Plates on Elastic Foundations. Journal of Applied Science and Engineering 23 (3), 439-452.

40. Ghannad, MA and Jahankhah, H 2004. Strength reduction factors considering soil-structure interaction. In $13^{\text {th }}$ World Conference on Earthquake Engineering, Vancouver, B.C., Canada, August, 1-6, 1-7.

41. Fernandez-Sola, L and Galindo, GM 2015. Behavior of RC Frames with hysteretic damper considering dynamic soil structure interaction. In The $11^{\text {th }}$ Canadian Conference on Earthquake Engineering, Victoria, BC, Canada, July, 21-24, publisher Canadian Association for Earthquake Engineering, 110

42. Barabash, MS and Pikul, AV 2017. Material damping in dynamic analysis of structures. International Journal for Computational Civil and Structural Engineering 13 (3), 13-18.

43. Roby, M 2017. Practice of soil-structure interaction under static and seismic stresses. Some aspects of nonlinear seismic SSI (Pratique de l'interaction sol-structure sous sollicitations statiques et sismiques. Quelques aspects de l'ISS sismique non linéaire). Journée technique du CFMS, France, December 05, 1-55.

44. Hamidi, B, Nikraz, H and Varaksin, S 2009. A review of impact oriented ground improvement techniques. Australian Geomechanics Journal 44 (2), 17-24.

45. Brûlé, S and Duquesnoy, S 2016. Change of ground type by means of dynamic compaction: consequence on the calculation of seismic loadings. Innovative Infrastructure Solutions 1 (39), 1-7.

Editor received the manuscript: 20.06.2020 